University of Nebraska - Lincoln DigitalCommons@University of Nebraska - Lincoln

2015

\title{
Hedge fund replication with a genetic algorithm: breeding a usable mousetrap
}

Brian C. Payne

Jiri Tresl

Follow this and additional works at: https://digitalcommons.unl.edu/financefacpub

Part of the Finance and Financial Management Commons

This Article is brought to you for free and open access by the Finance Department at DigitalCommons@University of Nebraska - Lincoln. It has been accepted for inclusion in Finance Department Faculty Publications by an authorized administrator of DigitalCommons@University of Nebraska Lincoln. 


\title{
Hedge fund replication with a genetic algorithm: breeding a usable mousetrap
}

\author{
BRIAN C. PAYNE $\dagger$ and JIRI TRESL* + \\ $\dagger$ US Air Force Academy, Colorado Springs, CO, USA \\ \$Department of Finance, University of Nebraska, Lincoln, NE 68588, USA
}

(Received 27 January 2014; accepted 9 October 2014)

\begin{abstract}
This study tests the performance of 14 hedge fund index clones created using parsimonious outof-sample replication portfolios consisting solely of easily accessible assets. We employ a genetic algorithm to integrate two traditional hedge fund replication methods, the factor-based and payoff distribution replication methods, and evaluate over 4500 commonly held stocks, bonds and mutual funds as replicating portfolio components. In-sample performance indicates that hedge funds have return series similar to portfolios of commonly held assets, and out-of-sample results provide evidence that the in-sample relationships can hold with infrequent rebalancing. This hedge fund replication attempt rates well relatively to prior efforts as 11 replicating portfolios have out-of-sample correlation values of at least $60 \%$. Overall, these results show promise for using a genetic algorithm technique to replicate hedge fund returns.
\end{abstract}

Keywords: Hedge Funds; Replication; Genetic Algorithm

JEL Classification: C61, G11

\section{Introduction}

An effective hedge fund replication method is relevant for many parties, including investors, hedge fund managers and regulators.§ Retail investors can gain access to hedge fund such as returns to enhance and diversify their portfolios. Regulators can get insight into the types of strategies that hedge funds are using. This regulatory access-at-a-distance would also please hedge fund managers, reducing requirements that they divulge proprietary strategies. $\int$ This paper demonstrates the effectiveness of using a genetic algorithm (GA) technique to replicate, or clone, hedge fund returns with easily accessible stocks, bonds and mutual funds.ll

This hedge fund replication analysis springs from prior replication research. Fung and Hsieh (2002) point out that 'hedge fund managers typically transact in asset markets

\section{*Corresponding author. Email: jtres12@unl.edu}

\$Hedge funds are investment products available to institutional (e.g. pension funds and endowments) and accredited individual investors (i.e. income over $\$ 200,000$ and greater than $\$ 1$ million in net worth beyond a primary residence), according to the SEC. Over 9500 hedge funds existed as of 2011, holding a record-level $\$ 2$ trillion-plus in total assets.

Thttp://www.hedgefundresearch.com/pdf/pr_20120313.pdf.

$\|$ Amenc et al. (2008) provide a good summary review of passive hedge fund replication methods. similar to those used by traditional managers', which they logically follow with the question of how these hedge fund managers 'deliver return characteristics that are different' from those of the underlying asset classes. Hasanhodzic and Lo (2007) highlight that the 'replicating factors proposed are only a small subset of the many liquid instruments that are available to the institutional investor. By expanding the universe of factors ... it should be possible to achieve additional improvements in performance ...'

Past academic literature has also shown that cloning hedge fund returns using risk factors is a worthy endeavour, but that it is challenging without the use of derivative contracts (e.g. futures and forwards). $\dagger \uparrow$ Therefore, replicating these funds with explicit stocks, bonds and mutual funds provides a more nuanced and practical element to the hedge fund replication task. It is one thing to say hedge funds write put options on the market; it is quite another to say an Equity Market Neutral hedge fund took the equivalent of a large position in the Bond Fund of America and a small short position in Central Pacific Financial Corporation over the prior five years (i.e. $R^{2}$ is 0.947 ) and further that this relationship holds relatively well over the subsequent 12 months.

†Cloning, very simply, involves replicating a hedge fund's return performance without the explicit knowledge of the hedge fund's investment holdings. 


\begin{tabular}{|c|c|c|c|c|}
\hline \multirow[b]{2}{*}{ Study } & \multirow[b]{2}{*}{ Method } & \multirow[b]{2}{*}{ Approach } & \multicolumn{2}{|c|}{ Results Summary } \\
\hline & & & Overview & Out-of-Sample $\mathbf{R}^{2}$ \\
\hline $\begin{array}{l}\text { Fung and Hsich } \\
(2002)\end{array}$ & $\begin{array}{l}\text { Factor } \\
\text { Based }\end{array}$ & $\begin{array}{c}\text { The authors studied fixed income } \\
\text { strategies. }\end{array}$ & In-sample $\mathrm{R}^{2}$ ranged between $59-79 \%$. & Not Provided \\
\hline $\begin{array}{l}\text { Agarwal and Naik } \\
\text { (2004) }\end{array}$ & $\begin{array}{l}\text { Factor } \\
\text { Based }\end{array}$ & $\begin{array}{l}\text { The authors studied eight } \\
\text { different strategies with buy and } \\
\text { hold and option based factors. }\end{array}$ & $\begin{array}{l}\text { In-sample } \mathrm{R}^{2} \text { ranged between } 41-92 \% \text {. } \\
\text { Statistically indifferent return } \\
\text { differences between the replication } \\
\text { portfolios and the hedge fund indices. }\end{array}$ & Not Provided \\
\hline $\begin{array}{l}\text { Jaeger and Wagner } \\
(2005)\end{array}$ & $\begin{array}{l}\text { Factor } \\
\text { Based }\end{array}$ & $\begin{array}{l}\text { The authors used multi-linear } \\
\text { asset class factor models for the } \\
\text { in sample replication. The } \\
\text { replicating factor strategy used } \\
\text { macro variables. }\end{array}$ & $\begin{array}{c}\text { In-sample } \mathrm{R}^{2} \text { ranged between } 35-89 \% \text {. } \\
8 \text { out of } 9 \text { non-investable indices } \\
\text { outperformed the clones. } 6 \text { out of } 7 \\
\text { investible indices underperformed the } \\
\text { clone. }\end{array}$ & Not Provided \\
\hline $\begin{array}{l}\text { Hasanhodzic and } \\
\text { Low (2007) }\end{array}$ & $\begin{array}{l}\text { Factor } \\
\text { Based }\end{array}$ & $\begin{array}{l}\text { The authors used } 6 \text { factors to } \\
\text { study } 11 \text { strategies. }\end{array}$ & In-sample $\mathrm{R}^{2}$ were less than $60 \%$. & $\begin{array}{l}\text { Out-of-sample } \mathrm{R}^{2} \text { were less } \\
\text { than } 50 \% \text { for the majority } \\
\text { of replications. }\end{array}$ \\
\hline Amin and Kat (2003) & $\begin{array}{l}\text { Moment } \\
\text { Based }\end{array}$ & $\begin{array}{l}\text { The authors used Monte Carlo } \\
\text { simulations for the near-month } \\
\text { S\&P } 500 \text { futures contracts. }\end{array}$ & $\begin{array}{l}12 \text { out of } 13 \text { hedge indices were } \\
\text { outperformed by clones. }\end{array}$ & Not Provided \\
\hline $\begin{array}{l}\text { Kat and Palaro (2005, } \\
2006 a, 2006 b)\end{array}$ & $\begin{array}{l}\text { Moment } \\
\text { Based }\end{array}$ & $\begin{array}{l}\text { The authors replicate several } \\
\text { statistical moments of hedge } \\
\text { fund returns. }\end{array}$ & $\begin{array}{l}\text { The quality of the replication improved } \\
\text { with long-term testing periods. }\end{array}$ & Not Provided \\
\hline
\end{tabular}

Panel B: Summary of In-Sample and Out-of-Sample $R^{2}$ of the Hybrid Method

\begin{tabular}{|c|c|c|c|c|}
\hline \multirow[b]{2}{*}{ Type } & \multirow[b]{2}{*}{ Method } & \multirow[b]{2}{*}{ In-Sample $\mathbf{R}^{2}$ Range } & \multicolumn{2}{|c|}{ Out-of-Sample $\mathbf{R}^{2}$} \\
\hline & & & $\mathbf{R}^{2}$ Entire Period & $R^{2}$ Post-2001 \\
\hline Hedge Fund Index & Hybrid & $0.708-0.914$ & 0.507 & 0.743 \\
\hline Convertible Arbitrage & Hybrid & $0.507-0.895$ & 0.504 & 0.573 \\
\hline Dedicated Short Bias & Hybrid & $0.733-0.920$ & 0.486 & 0.423 \\
\hline Emerging Markets & Hybrid & $0.754-0.935$ & 0.752 & 0.712 \\
\hline Equity Market Neutral & Hybrid & $0.461-0.947$ & 0.045 & 0.041 \\
\hline Event Driven & Hybrid & $0.700-0.883$ & 0.446 & 0.517 \\
\hline Event Driven Distressed & Hybrid & $0.692-0.897$ & 0.401 & 0.483 \\
\hline Event Driven Multi-Strategy & Hybrid & $0.722-0.842$ & 0.498 & 0.537 \\
\hline Event Driven Risk Arbitrage & Hybrid & $0.633-0.793$ & 0.321 & 0.394 \\
\hline Fixed Income Arbitrage & Hybrid & $0.482-0.876$ & 0.364 & 0.476 \\
\hline Global Macro & Hybrid & $0.429-0.835$ & 0.020 & 0.105 \\
\hline Long/Short Equity & Hybrid & $0.831-0.933$ & 0.731 & 0.771 \\
\hline Managed Futures & Hybrid & $0.482-0.653$ & 0.025 & 0.013 \\
\hline Multi-Strategy & Hybrid & $0.453-0.906$ & 0.496 & 0.692 \\
\hline
\end{tabular}

Figure 1. Comparison to previous work.

Note: This figure summarizes studies that previously replicated hedge funds (Panel A) and the in-sample and out-of-sample results using the hybrid method in this paper (Panel B). In-Sample $R^{2}$ Range is the range of the coefficient of determination during the in-sample periods. Out-of-Sample $R^{2}$ Entire Period is the coefficient of determination for the overall out-of-sample period from January 1999 to December 2010. Out-of-Sample $R^{2}$ Post-2001 is the coefficient of determination for the 108-month out-of-sample period from January 2002 to December 2010.

This study creates parsimonious out-of-sample replication portfolios consisting solely of easily accessible assets to test the performance as clones of hedge fund indexes and to examine whether hedge fund returns are different from portfolios of traditional assets. We take advantage of the GA methodology to integrate two traditional hedge fund replication methods, the factor-based (e.g. Amenc et al. 2003) and pay-off distribution replication (Amin and Kat 2003) methods, and evaluate over 4500 commonly held stocks, bonds and mutual funds as replicating portfolio components.

Using these traditional methods in isolation can present challenges in terms of replication. In insolation, factor-based and moments-based methods suffer due to the variation of hedge fund exposures to risk factors and due to the time-period dependency of the hedge fund returns. $\uparrow$ A GA technique alleviates the problem by combining the information from both methods. This technique enriches the toolbox of hedge fund replication methods and our implementation of a GA approach that simultaneously combines both methods that can help overcome such challenges.t

$\dagger$ See Amenc et al. (2008) and Hasanhodzic and Lo (2007) for further discussion about these challenges with the factors and moments methods.

$\$$ Other techniques currently becoming more popular are dynamic modelling methods. We do not consider those in this study. 
Panel A: Hedge Fund Index 1: Hedge Fund Index

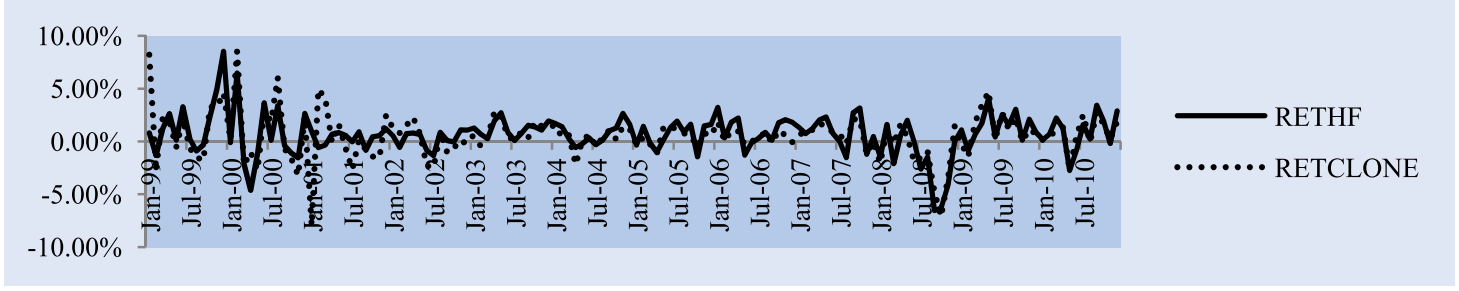

Panel B: Hedge Fund Index 2: Convertible Arbitrage

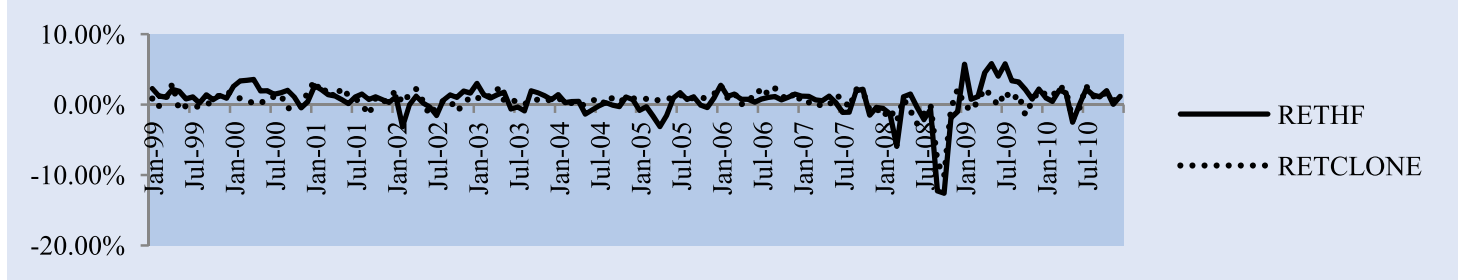

Panel C: Hedge Fund Index 3: Dedicated Short Bias

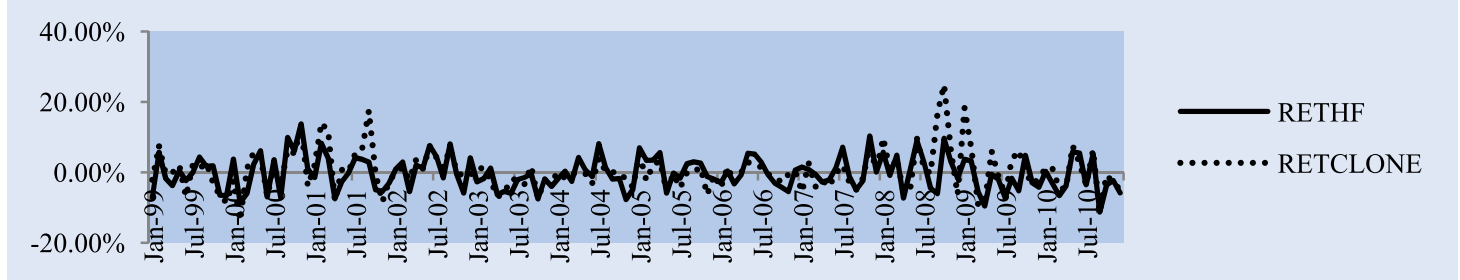

Panel D: Hedge Fund Index 4: Emerging Markets

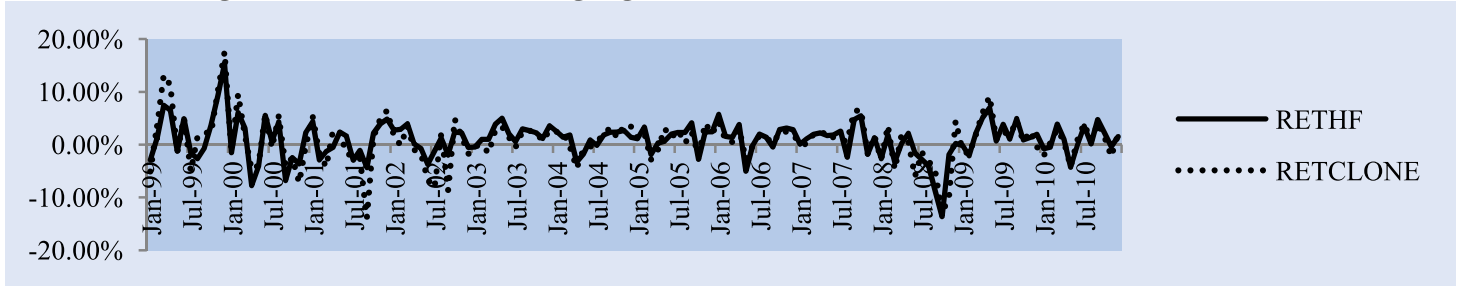

Panel E: Hedge Fund Index 5: Equity Market Neutral

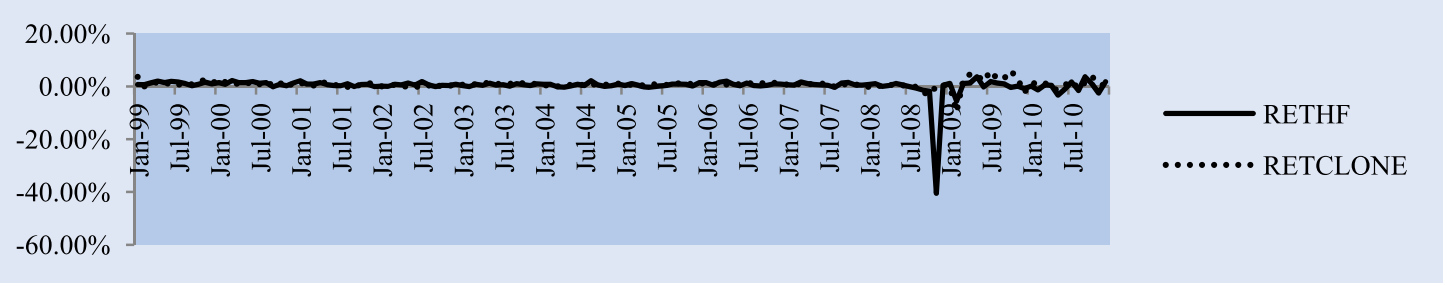

Figure 2. Out-of-sample hedge fund index and replicating portfolio performance.Note: This figure shows the out-of-sample monthly return performance of the five-asset replicating portfolio (RETCLONE) and the target hedge fund index (RETHF) from January 1999 to December 2010. The five-asset replicating portfolio returns are generated using a genetic algorithm (GA). Panels A through $\mathrm{N}$ provide respective performance data for the 14 different hedge fund indexes described in table 1.

There are many advantages to using genetic algorithms to address vexing problems such as hedge fund replication, particularly considering the aforementioned factor and moments methods. First, genetic algorithms permit complete objective function flexibility. Whereas multiple regression (e.g. factor-based) approaches typically satisfy a single objective function, which is to minimize the mean-squared error between the estimated and actual return series, the genetic algorithm process can simultaneously address other objective function inputs. For instance, it permits one to incorporate both factor-based and matching moments criteria into a single objective function. Additionally, since the genetic algorithm is not a hill-climbing algorithm, it is capable of handling non-linear and discontinuous objective functions. Besides their objective function flexibility, genetic algorithms are computationally efficient. They utilize a method called 'implicit parallel processing' (described in the methodology section) to winnow the potential solution set rather quickly, which is advantageous for timesensitive practitioners, since it allows one to analyse a very large search space very efficiently (see Bauer (1994) and Holland (1975) for additional discussion and mathematical proofs). Unfortunately, the lack of monthly time series data points and resulting degrees of freedom make it impossible 
Panel F: Hedge Fund Index 6: Event Driven

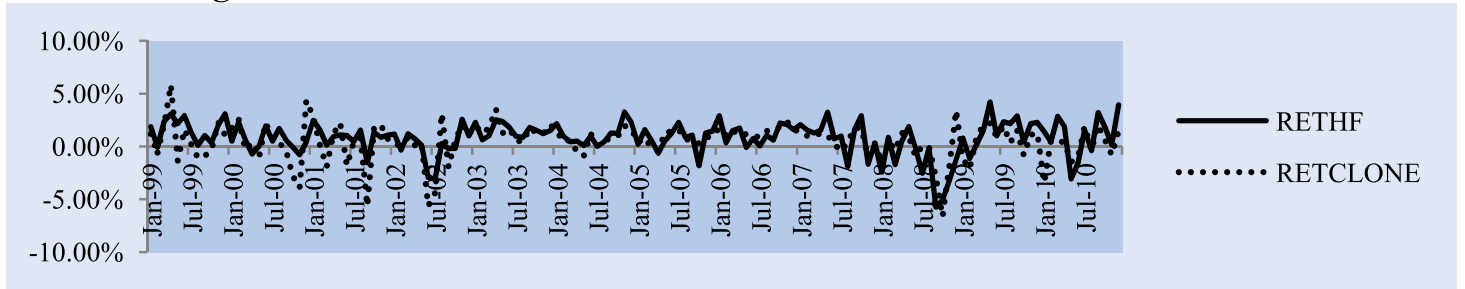

Panel G: Hedge Fund Index 7: Event Driven Distressed

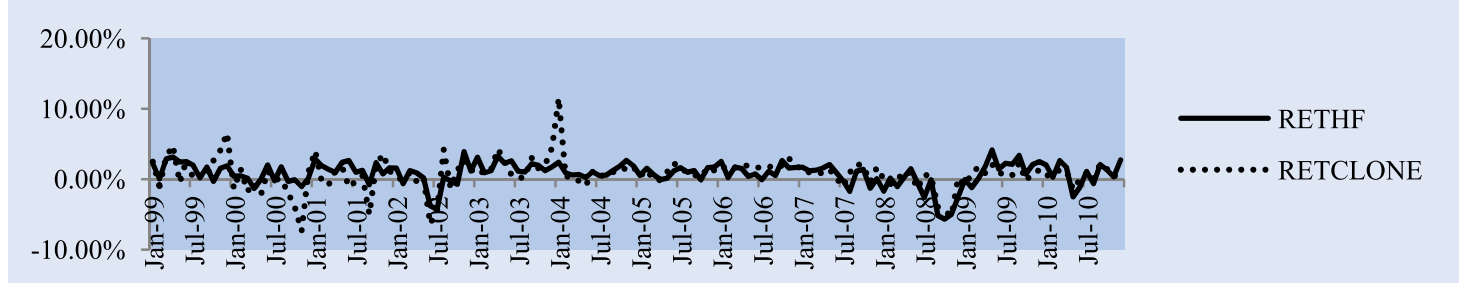

Panel H: Hedge Fund Index 8: Event Driven Multi-Strategy

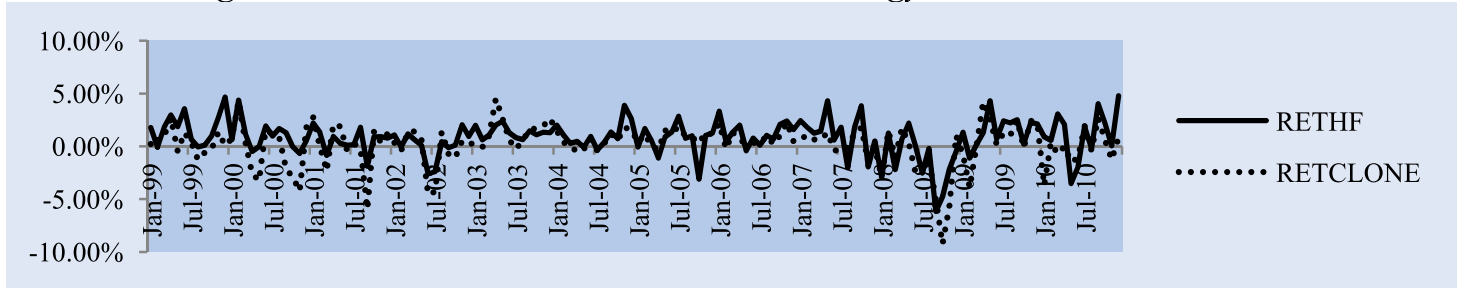

Panel I: Hedge Fund Index 9: Event Driven Risk Arbitrage

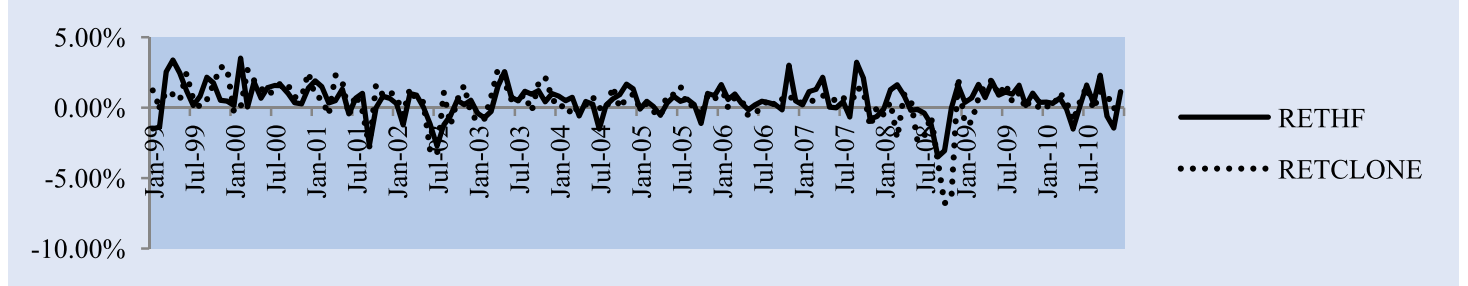

Panel J: Hedge Fund Index 10: Fixed Income Arbitrage

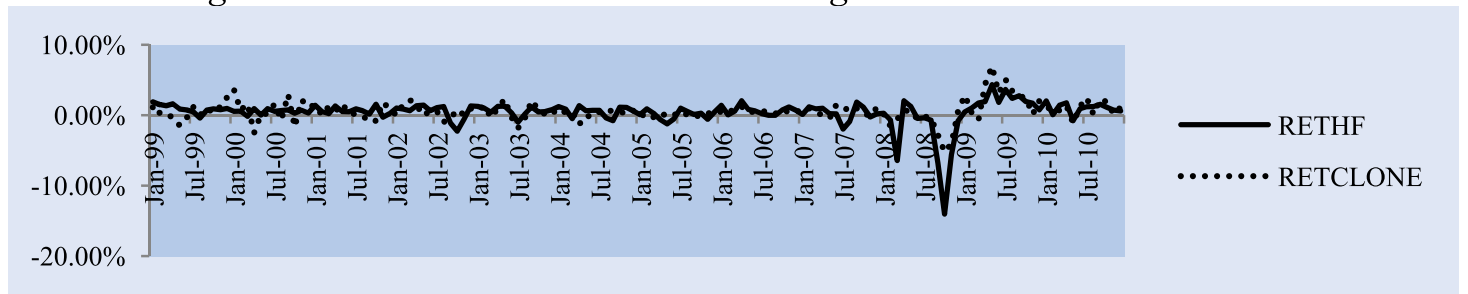

\section{Panel K: Hedge Fund Index 11: Global Macro}

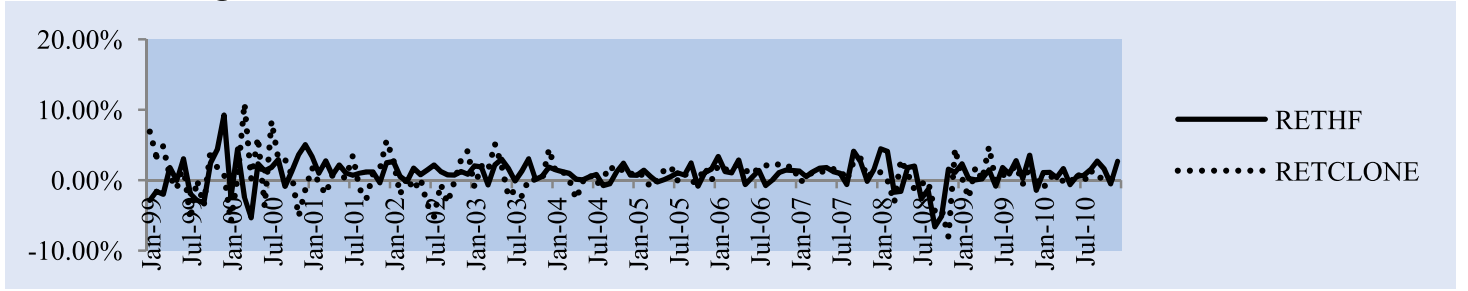

Figure 2. (Continued).

to run a single linear regression using all 4509 assets and weighting a portfolio based on the assets that load. More specifically, using hedge fund index return data from 1994 to 2010 yield 204 monthly returns. This finite series limits the potential mimicking assets available before exhausting the model's degrees of freedom. And, a complete analysis of all potential asset permutations could take many months to complete, making any cloning strategy obsolete before one could implement it. $\dagger$ GAs enable a rather thorough analysis of the assets one could use to clone hedge funds,

$\uparrow$ As a simple example, if one wanted to select 5 assets from a population of 4509 assets, there exist over 15 quadrillion unique combinations. If a computer processes one billion five-asset multiple regressions per second [see equation (2)], then an exhaustive analysis would take almost 6 months to complete. 


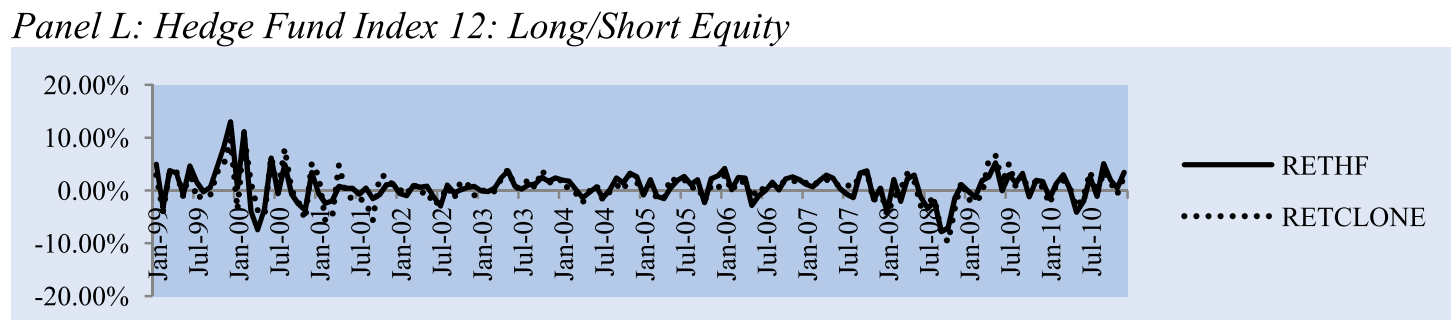

\section{Panel M: Hedge Fund Index 13: Managed Futures}

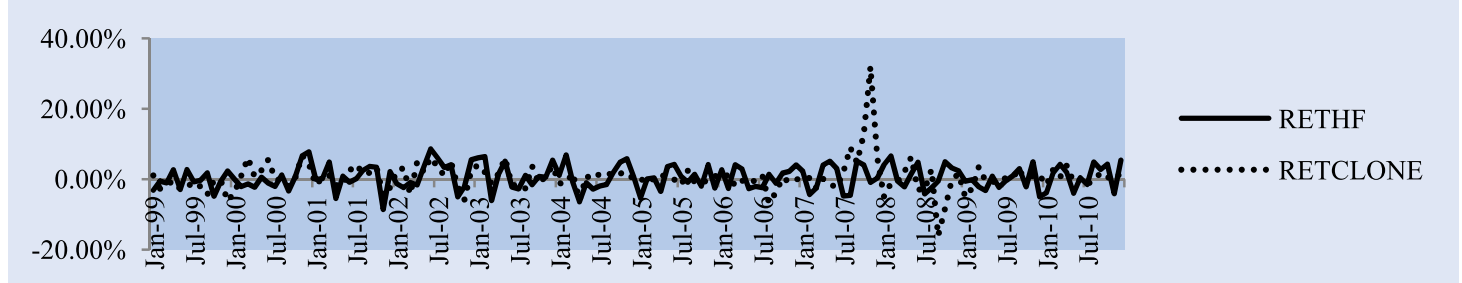

\section{Panel N: Hedge Fund Index 14: Multi-Strategy}

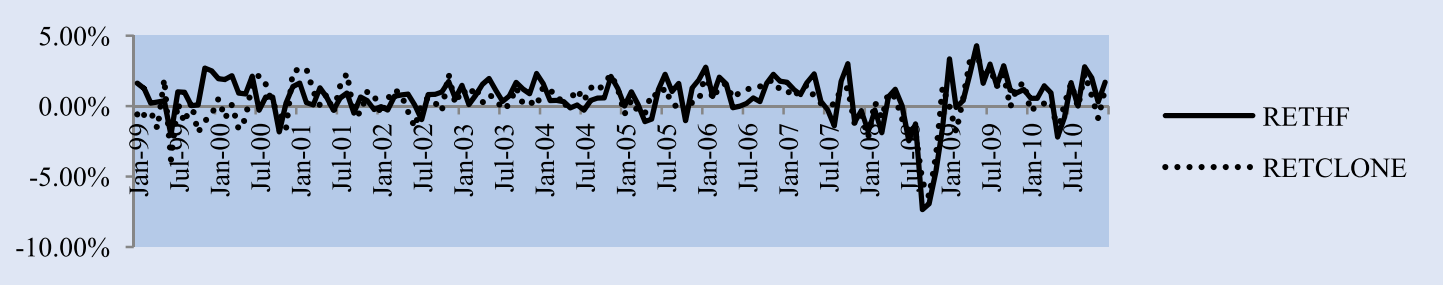

Figure 2. (Continued).

as they do not limit one to a parsimonious list of factors nor do they limit one to choose between the typical methods of matching period-by-period performance (i.e. the factor method) or matching a distribution (i.e. the moments method). Thus, due to the versatile objective function and computational efficiency, a genetic algorithm makes it feasible to glean this deeper and practical understanding that is much needed in the hedge fund industry. $\dagger$ The goal of this study is not to claim that our objective function is optimal, but instead to show the power and versatility of the genetic algorithm to implement the desired cloning strategy with a modestly sized portfolio.

We create myriad five-asset portfolios using a basic genetic algorithm to test the performance of clones of, first, an overall hedge fund index, and then 13 various hedge fund indexes representing different strategies. $\$$ We consider

$\dagger$ Some studies have implemented GAs, however, this study clearly differs from them. This study tracks hedge funds, whereas studies such as Rafaely and Bennell (2006) compare GAs to quadratic programming to optimize tracking FTSE 100 index funds. Also, while Gibson Brandon and Gyger (2011) employ a GA to solve for a portfolio's optimal hedge fund allocation in the presence of liquidity risk and investor risk preferences, this paper uses the GA tool for the more general case of mimicking hedge fund performance independent of risk preferences and sources.

\$Convertible Arbitrage, Dedicated Short Bias, Emerging Markets, Equity Market Neutral, Event Driven, Event Driven Distressed, Event Driven Multi-Strategy, Event Driven Risk-Arbitrage, Fixed Income Arbitrage, Global Macro, Long/Short Equity, Managed Futures, and Multi-Strategy. The hedge fund indexes come from Dow Jones Credit Suisse and are available at www.hedgeindex. com. simultaneously matching month-by-month performance and matching the return distribution with mimicking portfolios in the in-sample periods and then analyse the out-of-sample results. Sample data are from January 1994 to December 2010. The in- and out-of-sample periods occur on a rolling basis. Each in-sample (out-of-sample) period lasts 60 (12) months. For instance, using in-sample data from January 1994 to December 1998, the first out-of-sample results occur from January 1999 to December 1999. We then roll forward to the next out-of-sample period, from January 2000 to December 2000, using the in-sample period from January 1995 to December 1999. The entire out-of-sample period spans 12 calendar years from January 1999 to December 2010.

Our results indicate that these hedge fund returns as a whole are not different from portfolios of traditional asset classes. The in-sample performance of the best genetic algorithm solutions indicates that hedge funds exhibit return series similar to portfolios of commonly held assets. The out-of-sample results provide evidence of this technique's applied value, since the in-sample relationships can hold going forward. Across the 12-year out-of-sample period, a statistical comparison of returns distributions with the target hedge fund indices showed that the GA factor-based method replicated 5 of 14 indices, the moments method replicated 9 of 14 indices and the hybrid method replicated 9 of 14 indices. When analysing the out-of-sample correlations of the hybrid method alone, 9 out of 14 replicating portfolios have values above $60 \%$ (table 4). Specifically, two replicating portfolios have outof-sample correlations above $80 \%$, three have correlations in the $70 \%$ range and four in the $60 \%$ range. These 
Table 1. Hedge fund indexes.

\begin{tabular}{|c|c|c|}
\hline & Type & Measures aggregate performance of: \\
\hline 1 & Hedge fund index & $\begin{array}{l}\text { Asset-weighted hedge fund index that uses the Credit Suisse Hedge Fund Database, which tracks } \\
\text { approximately } 8000 \text { funds having at least } \$ 50 \text { million in assets under management (AUM), a 12-month } \\
\text { history and audited financials. All other indexes are subsets of this one. }\end{array}$ \\
\hline 2 & Convertible arbitrage & $\begin{array}{l}\text { Convertible arbitrage funds. These funds seek profits from purchasing convertible securities and shorting the } \\
\text { corresponding stock when there is a pricing error in the conversion factor of the security. }\end{array}$ \\
\hline 3 & Dedicated short bias & $\begin{array}{l}\text { Dedicated short bias funds. Typically take more short than long positions, earning returns from a net short } \\
\text { exposure to long and short equities. }\end{array}$ \\
\hline 4 & Emerging markets & $\begin{array}{l}\text { Emerging markets funds. Typically invest in currencies, equities, debt and other instruments of countries } \\
\text { with emerging or developing markets, as measured by GDP per capita. }\end{array}$ \\
\hline 5 & $\begin{array}{l}\text { Equity market } \\
\text { neutral }\end{array}$ & $\begin{array}{l}\text { Equity market neutral funds. Typically take both long and short stock positions to reduce market risk } \\
\text { exposure (i.e. a zero beta). Number of subsectors, such as statistical arbitrage, quantitative long/short, } \\
\text { fundamental long/short and index arbitrage. Often use leverage. }\end{array}$ \\
\hline 6 & Event driven & Event driven funds. See subsequent event driven categories. \\
\hline 7 & $\begin{array}{l}\text { Event driven } \\
\text { distressed }\end{array}$ & $\begin{array}{l}\text { Event driven funds focused on distressed situations. Typically invest across the capital structure of } \\
\text { companies subject to financial or operational distress or bankruptcy proceedings. Strategy generally long } \\
\text { biased in nature, but it can vary. }\end{array}$ \\
\hline 8 & $\begin{array}{l}\text { Event driven multi- } \\
\text { strategy }\end{array}$ & $\begin{array}{l}\text { Multi-strategy event driven funds. Typically invest in combination of event driven equities and credit. Many } \\
\text { sub-strategies for both equity and credit investing. Typically have flexibility to pursue event investing across } \\
\text { different asset classes and to take advantage of shifts in economic cycles. }\end{array}$ \\
\hline 9 & $\begin{array}{l}\text { Event driven risk } \\
\text { arbitrage }\end{array}$ & $\begin{array}{l}\text { Risk arbitrage funds. Typically attempt to capture spreads in merger or acquisition transactions with public } \\
\text { companies after announcement of terms. Spread is the difference between transaction bid and trading price. } \\
\text { Target stock typically trades at discount to bid price to account for probability of deal failure. }\end{array}$ \\
\hline 10 & $\begin{array}{l}\text { Fixed income } \\
\text { arbitrage }\end{array}$ & $\begin{array}{l}\text { Fixed income arbitrage funds. Typically attempt to generate profits by exploiting inefficiencies and price } \\
\text { anomalies between related fixed income securities. Funds seek to limit volatility by hedging exposure to } \\
\text { market and interest rate risk. Many strategies. }\end{array}$ \\
\hline 11 & Global macro & $\begin{array}{l}\text { Global macro funds. Typically focus on extreme price valuations; often apply leverage to anticipated price } \\
\text { movements in equity, currency, interest rate and commodity markets. Much manager flexibility, with } \\
\text { approaches that are systematic models or discretionary. }\end{array}$ \\
\hline 12 & Long/short equity & $\begin{array}{l}\text { Long/short equity funds. Typically invest in both long and short sides of equity markets, focusing on } \\
\text { diversifying/hedging across sectors, regions or market capitalizations. Much manager flexibility. }\end{array}$ \\
\hline 13 & Managed futures & $\begin{array}{l}\text { Managed futures funds. Often referred to as commodity trading advisors (CTAs) and typically focus on } \\
\text { listed bond, equity, commodity futures and global currency markets. Typically systematic trading programs } \\
\text { relying on historical data and trends. Potentially use significant leverage with use of futures contracts. }\end{array}$ \\
\hline 14 & Multi-strategy & $\begin{array}{l}\text { Multi-strategy funds. Typically characterized by ability to allocate capital based on perceived opportunities } \\
\text { among several hedge fund strategies. Added diversification may reduce risk profile and help smooth returns, } \\
\text { reduce volatility and decrease asset class and single strategy risks. Multiple strategies possible. }\end{array}$ \\
\hline
\end{tabular}

Notes: This table summarizes the Dow Jones Credit Suisse Hedge Fund Indexes this paper seeks to replicate. Their return series and detailed descriptions are available at www.hedgeindex.com.

results further imply that hedge fund-like performance is available to the masses of retail investors.

Aggregating all results from this study shows the GA method is a valuable replication tool based on the general trends that emerge. The GA method in this paper generates high in- and out-of-sample $R^{2}$ values (table 4), relative both to past research (figure 1) and random portfolios, which we create for robustness purposes. For example, many of the in-sample $R^{2}$ values rate favourably relative to the mean $R^{2}$ values in the Hasanhodzic and Lo (2007) analysis and are closer to the maximum values shown in their study, which again are for individual hedge funds. These $R^{2}$ values also rate favourably compared with random portfolios, as the GA-generated value is in the top quartile in all 168 out-ofsample years represented by the 14 hedge funds in this study.

This study contributes to the hedge fund replication literature in three main ways. First, the results show that these hedge fund returns might not be different from portfolios of traditional asset classes, which confirm previous findings (e.g. Agarwal and Naik 2004). Second, it creates effective out-of-sample replication or cloning portfolios consisting solely of assets accessible by retail investors (i.e. stocks, mutual funds and government bonds). Finally, we present one possible objective function that synthesizes two hedge fund replication methods to demonstrate the powerful genetic algorithm methodology in hedge fund cloning.

This paper is organized as follows. Section 2 summarizes the background literature. Section 3 discusses the data. Section 4 explains the methodology. Sections 5 presents the results, and Section 6 concludes.

\section{Background}

A consistent tension exists between regulators such as the SEC, which seeks greater insight into hedge funds, and the hedge fund managers who want to keep a close hold on their trade secrets. The most recent trend is toward greater disclosure. In June 2011, the SEC adopted Dodd-Frank Act Amendments to the Investment Advisers 


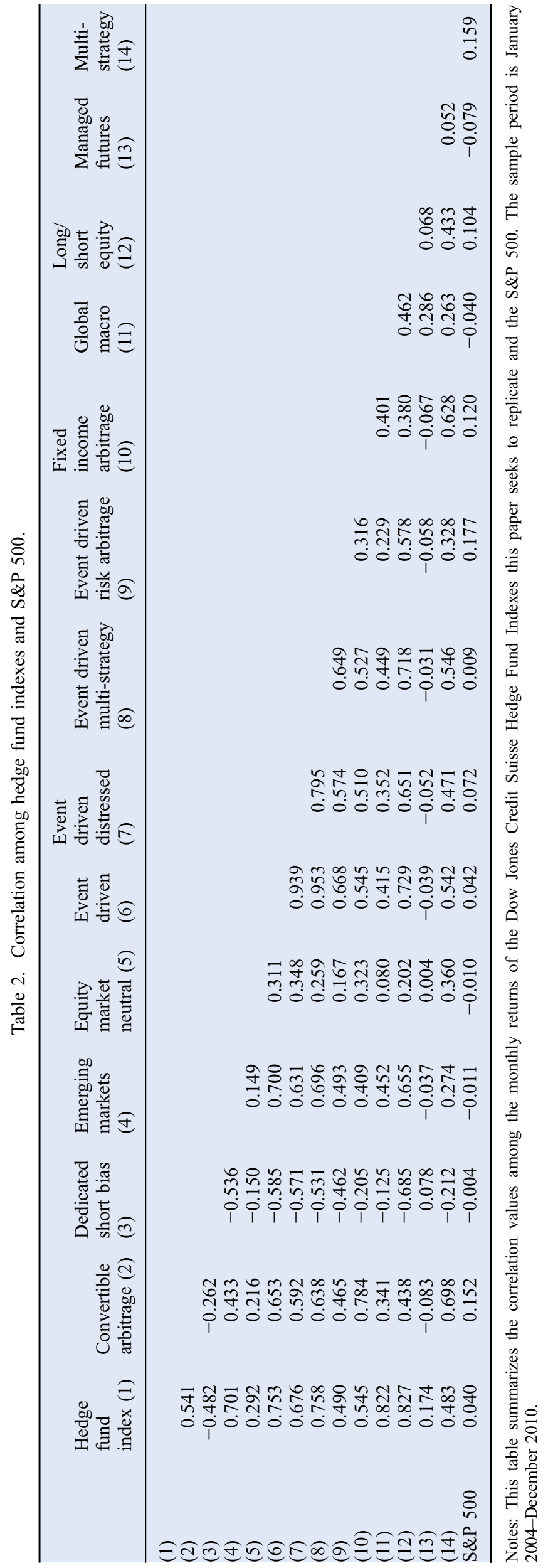


Act that in SEC Chairman Schapiro's words, 'give the Commission, and the public, insight into hedge fund and other private fund managers who previously conducted their work under the radar and outside the vision of regulators'. $\uparrow$ The result is the lead sentence in a March 2012 popular press article summarizing the current state of affairs for hedge fund managers: 'Hedge fund managers are increasingly nervous about getting a knock on the door from securities regulators now that a new rule requires them to register as investment advisers and provide lots of data about their inner workings as a result'.t Besides regulators, institutional investors such as pension funds desire, and sometimes require under state sunshine laws, greater transparency into hedge fund holdings and strategies.§ Hedge fund managers use nondisclosure agreements with such clients to protect their secret recipes, since any information divulgence decreases their control over where the information ultimately flows. Yet fund managers' arguments that disclosure could reduce their competitiveness could be baseless, according to Aggarwal and Jorion (2012). This study finds no significant performance difference between 'transparent' hedge funds that selectively disclose their holdings and hedge funds that do not disclose any information beyond the minimum requirements. Presuming the regulator-fund manager stand-off continues in spite of these results, an effective hedge fund replication process could mitigate the problem. It would allow investors to create synthetic hedge fund returns using investments they can access; it would provide regulators some insight into the types of strategies (asset classes, long or short positions, etc.) that hedge funds are using; and it could prevent hedge fund managers from having to divulge their proprietary strategies.

Some argue access to hedge funds, or at least their return characteristics, should not be limited to accredited and institutional investors. Retail investors themselves have shown demand for such products, according to Agarwal et al. (2009), who document that such 'hedged mutual funds' outperform traditional mutual funds, yet underperform hedge funds due to these hedge funds' improved incentives (i.e. performance-based fees) and regulatory advantages. While perhaps not to the level of larger investors, these retail investors also seek enough information about investment products to make educated investment decisions. Besides investors wanting access to hedge fund-like products, Houman B. Shadab argues retail investor access would make markets more complete and help sophisticated retail investors fend for themselves'. Given the unlikelihood that the SEC will ever permit retail investors to invest directly in hedge funds, a replication tool would satisfy existing

†http://www.sec.gov/news/press/2011/2011-133.htm. thttp://www.reuters.com/article/2012/03/28/us-hedgefunds-registra tion-idUSBRE82R1FH20120328.

$\S$ http://www.hflawreport.com/.

Thttp://www.law.nyu.edu/ecm_dlv/groups/public/@nyu law web site_journals_journal_of_legislation_and_public_policy/docu ments/documents/ecm_pro_058131.pdf; p. 319. demand and serve as a proxy for retail investors seeking hedge fund access.

Hedge fund replication efforts have become more prevalent over the past decade. Understanding the evolution means recognizing cloning efforts that typically involve three main methods, namely the factor method, the moments method (also called the payoff distribution approach) and the reverse engineering method. Despite the progress made and successes obtained using these three methods, Amenc et al. (2008) review the efforts to date and aptly summarize the state of hedge fund replication as 'still very much a work in progress'. This paper builds upon their suggestion that introducing novel techniques with parsimonious models can transform hedge fund replication from an 'attractive concept into a workable investment solution'.

\subsection{Factor method}

The factor method creates a replicating portfolio with a goal of matching the time series returns of a hedge fund target based on underlying factors, such as macroeconomic factors or characteristics-based factors. For instance, Amenc et al. (2003) implement a six-factor model that includes changes in T-bill yields, moving average of the US market returns, changes in the volatility index, NYSE volume, moving average of the world market returns and oil prices. Using possibly the superset of all factors, Goodworth and Jones (2007) narrow a list of a hundred factors down to five to eight via various screening techniques. Given their focus on five to eight factors, the GA model here remains parsimonious in its use of five investable assets.l Mechanically, implementing factors simply involves regressing the in-sample target hedge fund return series on the corresponding in-sample factor return series. The coefficient estimates, or factor betas, represent the weights one would invest in the respective factor series in the out-of-sample period. Other related works focus on hedged mutual funds (e.g. Agarwal et al. 2009; Chong and Phillips 2012). The former paper finds hedged mutual funds outperform (underperform) traditional mutual funds (hedge fund indexes) and the latter uses a proprietary methodology with 18 economic factors to generate portfolios of ETFs that clone seven hedged mutual funds across four different strategies. Without an explicit effort to clone

"Questions have arisen about the rationale for using five assets. One reason for doing so is that the modest size of the portfolio lends more credibility about the efficacy of the GA method. One would expect a better cloning capability with a greater number of assets. From a more applied perspective, the authors are familiar with a very large retirement plan that includes only five funds as its investment options. Many so-called life-cycle funds also use such a parsimonious mix of funds. The authors leave it to future efforts to explore the results' sensitivity to larger portfolios (as well as altered objective functions). 
hedge funds, they also show some data indicating a cloning portfolio outperforms three hedge fund index strategies that parallel this paper.

This factor method provides respectable ex-post results with limited out-of-sample success. For instance, using their six factors, Amenc et al. (2003) achieve in-sample $R^{2}$ values for hedge fund indexes that range from approximately $15-54 \%$. They measure out-of-sample performance based on a hit ratio that measures whether the factor model accurately predicts whether the hedge fund index return will increase or decrease. All hit ratios are above 50\%. Agarwal and Naik (2004) investigate eight multi-factor models using both option-based and buy-andhold strategies. Their risk factors are similar in concept to other authors, including, for example, a small cap stock factor (Russell 3000), the MSCI world excluding the US, the MSCI emerging markets, the Fama and French (1993) SMB and HML factors, the Carhart (1997) momentum factor, the default spread, corporate and government bond returns, commodities and currency. They also include at- and out-of-the-money put and call options on the S\&P 500. Their in-sample results include $R^{2}$ values of 41 to $92 \%$; out-of-sample return differences were statistically insignificant between the replicating series and the hedge fund indices. These authors discuss two challenges that individual investors face in replicating hedge funds as the market frictions of difficulties accessing derivatives markets - specifically, taking short positions - and leveraging to the same extent as hedge funds. While the method in this paper permits short positions, it removes the leverage friction, bringing the retail investor one step closer to an implementable strategy. $\dagger$ Additionally, while Agarwal and Naik (2004) acknowledges a short hedge fund history, which they address assuming stable systematic risk factor loadings, this paper spans extreme stock market events-the technology boom in the late $1990 \mathrm{~s}$ as well as the most recent recession.

Irrespective of the factor method's success, it faces implementation challenges, particularly for a retail investor who has to find an asset or a set of them that performs like SMB, HML or momentum. For instance, creating a momentum factor (see Takahashi and Yamamoto 2008) could prove burdensome to quantify - e.g. how many days, weeks or months of positive or negative returns before one trades? - or prohibitively expensive to implement based on transactions costs. Thus, the performance of factor-based models to date tends to be respectable, however, it happens for relatively short out-of-sample periods and presents implementation challenges. The GA method, here, addresses these issues.

$\uparrow$ Although this paper considers mutual funds because they have existed in quantity for a longer period than ETFs, it is possible to short ETFs that are similar to a subject mutual fund. (Nonendorsed) mutual fund to ETF conversion tools aid in this process (e.g. http://etfdb.com/tool/mutual-fund-to-etf/).

\subsection{Matching moments method}

The second method, known as the matching moments method, seeks to create replicating portfolios that match the target hedge fund's statistical moments (i.e. mainly the higher order ones that indicate active management performance, such as variance, skewness and kurtosis) over a particular time period. This method does not focus on matching week-to-week or month-to-month hedge fund return movements, but instead seeks to generate returns drawn from a statistically equivalent distribution as the hedge fund targets. Amin and Kat (2003) $\$$ trade mechanically between cash and the S\&P 500 using a complex option-based strategy with a goal of matching return distributions for the lowest cost. They create a fund replication technique whose return distributions match those of 13 target hedge fund indexes with mean returns that are higher than the funds in 12 of the 13 cases. With correlation values ranging between -0.078 and 0.684 , this replication technique does not focus on matching hedge fund performance on a period-by-period basis. The Kat and Palaro trilogy $(2005,2006 a, 2006 b)$ extends this earlier work by developing a copula-based replicating portfolio that goes beyond matching the hedge fund performance to also maintaining the relationship between a hedge fund and an investor's current portfolio. Using a replication portfolio consisting of the S\&P 500, the T-bond and Eurodollar futures, they show, respectively, that their dynamic trading method uses an 'exotic option' to replicate three major funds-of-funds using daily rebalancing between 1987 and 2004; that their method accurately replicates statistical return properties for hedge funds, emerging markets and commodities between 1995 and 2006; and that not more than about $18 \%$ of individual hedge funds outperform a synthetic portfolio investors could have created themselves using the three assets listed previously. Overall, the matching moments - or pay-off distribution-method works well considering its stated purpose, even though it begs the question of one's definition of 'replication'. We address this issue by valuing time series replication in the GA objective function.

\subsection{Reverse engineering method}

The third - and most obvious - method is commonly called the reverse engineering method. In this method, the intent of the clone is literally to mimic the stated hedge fund strategy. In general, these studies do not seek to replicate hedge fund performance for the sake of replication, but instead to evaluate funds' performance relative to similar funds or implementing such a strategy outside of the hedge fund itself. For instance, Mitchell and Pulvino (2001) mimic merger hedge fund arbitrage strategies by betting on merger outcomes over time, showing similar returns to their portfolio that arbitrages merger events and the hedge fund strategy that does the same. Similarly, Duarte et al. (2007)

\$These authors rely heavily on the Dybvig (1988) payoff distribution model. 
analyse fixed income arbitrage strategies both by creating their own arbitrage strategies and comparing the performance to actual fixed-income arbitrage hedge fund indexes. The results are comparable for both, indicating their created return series have effectively reverse engineered the hedge fund strategies. Despite these examples, in practice, perfectly buying and selling to match hedge fund holdings is highly challenging. Large hedge funds that are required to disclose by the SEC only have to do so quarterly, are allowed to report positions that are 60 days old, must provide data only on the types of assets they own versus the specific holdings and report non-publicly to the government's Financial Stability Oversight Council. $\dagger$ Therefore, reverse engineering is quite fund specific based on strategy, whereas the GA method presented here is more general, addressing all major fund category strategies.

\section{Data}

The Dow Jones Credit Suisse Hedge Fund Indexes capture data on over 8000 hedge funds each having at least $\$ 50$ million in assets under management. This study focuses on replicating or cloning 14 of these hedge fund indexes that represent a wide range of techniques and strategies. The 14 indexes include: Hedge Fund Index; Convertible Arbitrage; Dedicated Short Bias; Emerging Markets; Equity Market Neutral; Event Driven; Event Driven Distressed; Event Driven Multi-Strategy; Event Driven Risk Arbitrage; Fixed Income Arbitrage; Global Macro; Long/Short Equity; Managed Futures; and Multi-Strategy. Table 1 lists these fund types and shares a brief description of their respective strategies. Table 2 provides their correlation values.

To clone the listed hedge fund index series, we permit the genetic algorithm to select from 4509 possible assets. This list includes 2804 mutual funds, 1689 individual stocks and nine bond series from CRSP. Note, many of the mutual funds are strictly bond funds or include bonds as balanced funds. $\S$

These potential cloning assets have return series that exist during the 1994-2010 sample period. The candidate assets and their respective reference numbers are available upon request.

\footnotetext{
†http://www.nytimes.com/2011/10/27/business/s-rule-lifts-lid-onhedge-funds.html?pagewanted=all.

†See www.hedgeindex.com for additional details on the Dow Jones Credit Suisse Hedge Fund Indexes.

§Additionally, we allow seven of the commonly referenced 'factors' from academic literature into the 'gene pool' that will form our five-asset portfolios. These factors include SMB, HML, Carhart's momentum factor UMD, excess market return, default premium, term premium and the VIX return. The VIX return series, SMB, HML and UMD come from the CRSP database. The excess market return, default premium and term premium come from the St. Louis Federal Reserve Economic Data (FRED) database and were constructed based upon Pontiff and Shall (1998). Incidentally, these common risk factors rarely find their way into the best fit cloning portfolios.
}

\section{Methodology: genetic algorithm}

A genetic algorithm (GA) is an iterative optimization method that generates solutions using a Darwinian 'survival of the fittest' process, involving both natural selection and mutation. The major steps in the GA include: (1) generating an initial solution set; (2) evaluating each solution's 'fitness level' relative to the other solutions; (3) allowing the best solutions to 'breed' among themselves; (4) introducing mutations to replace any 'non-breeding' members; and (5) beginning again with step (2). If allowed to progress ad infinitum, this iterative process generally leads to a single solution when the best fit solution eventually breeds out any inferior solutions. Acknowledging, we provide only a brief summary of GAs here, we refer the interested reader to Bauer (1994) for a more exhaustive treatment and Holland (1975) for the mathematical proofs behind the methods.

There are many advantages to using GAs to address vexing problems such as hedge fund replication, particularly considering the aforementioned factor and moments methods. First, GAs permit complete objective function flexibility. Whereas, multiple regression (e.g. factor based) approaches typically satisfy a single objective function, which is to minimize the mean-squared error between the estimated and actual return series, the GA process can simultaneously address other objective function inputs. For instance, it permits one to incorporate both factor-based and matching moments criteria into a single objective function. Additionally, since the GA is not a hill-climbing algorithm, it is capable of handling non-linear and discontinuous objective functions. Besides their objective function flexibility, GAs offer an advantage of computational efficiency. They utilize a method called 'implicit parallel processing' (described later) to winnow the potential solution set rather quickly. Unfortunately the lack of data and degrees of freedom make it impossible to run a single linear regression using all 4509 assets and weighting a portfolio based on the assets that load. More specifically, using hedge fund index return data from 1994 to 2010 yields 204 monthly returns. This finite series limits the potential mimicking assets available before exhausting the model's degrees of freedom. In summary, GAs, thus, facilitate a rather thorough analysis of the assets one could use to clone hedge funds, as it does not limit one to a parsimonious list of factors, nor does it limit one to choose between the typical methods of matching period-by-period performance or matching a distribution.

As with any optimization method, a genetic algorithm begins with choosing an objective function. In this application of replicating hedge funds, it is possible to focus efforts on either the factor method of matching period-byperiod performance or the matching moments method, which seeks a cloning portfolio with the same return distribution as the target hedge fund. Equation (1) shows the

IAs a simple example, if one wanted to select five assets from a population of 4509 assets, there exist over.15 quadrillion unique combinations. If a computer processes one billion five-asset multiple regressions per second [see equation (2)], then an exhaustive analysis would take almost six months to complete. 
Table 3. Distribution matching results from Kolmogorov-Smirnov test.

\begin{tabular}{llll}
\hline & \multicolumn{2}{c}{ Replication method } \\
\cline { 2 - 4 } & Factors $\left(R^{2}\right)$ & Hybrid & Moments (Mean/variance) \\
\hline Hedge fund index & Same & Same & Same \\
Convertible arbitrage & Different** & Different** & Different* \\
Dedicated short bias & Same & Same & Same \\
Emerging markets & Same & Same & Same \\
Equity market neutral & Different** & Different* & Same \\
event driven & Different*** & Same & Different* \\
Event driven distressed & Different*** & Same & Same \\
Event driven multi-strategy & Different*** & Different*** & Same \\
Event driven risk arbitrage & Same & Same & Same \\
Fixed income arbitrage & Different*** & Different* & Different*** \\
Global macro & Different*** & Different** & Same \\
Long/short equity & Same & Same & Same \\
Managed futures & Different** & Same & Different* \\
Multi-strategy & Different*** & Same & Different* \\
\hline
\end{tabular}

Notes: This table summarizes the results from a two-tailed Kolmogorov-Smirnov test for whether the out-of-sample distribution of monthly returns for cloning portfolios differs significantly from the distribution of monthly returns for the target hedge fund (HF). Mimicking portfolios are formed using a genetic algorithm approach. 'Different' ('Same') indicates rejection of (failure to reject) the null hypothesis that the distributions are identical. The factors method creates a mimicking portfolio that maximizes the in-sample $R^{2}$ value. The moments method minimizes the in-sample difference between mean returns and the standard deviation. The hybrid method equally weights the factors and moments methods. Hedge fund index returns come from the Dow Jones Credit Suisse Indexes website (www.hedgeindex.com). $* * *, * *$ and $*$ indicate significance at the 1,5 and $10 \%$ levels, respectively.

objective function - or fitness function in genetic algorithm terms - in this paper. hedge fund in both mean space and in risk level, or variance space. The pre-multiplied integers-75 and 25 -in this

$$
\text { Fitness }=\omega_{\text {factor }}\left(1-R^{2}\right)+\omega_{\text {distribution }}\left(75 *\left|\mu_{\mathrm{HF}}-\mu_{\text {clone }}\right|+25 *\left|\sigma_{\mathrm{HF}}-\sigma_{\text {clone }}\right|\right)
$$

This fitness function provides a single measure of the insample performance for any clone portfolio relative to its hedge fund target. $\uparrow$ The fitness function has two main terms, each with a weighting factor, $\omega_{i}$. The first term represents the factor distribution method, whereby the higher insample coefficient of determination, or $R^{2}$, value indicates a greater fitness level. Ignoring the weight, this first term clearly takes a value between zero and one. The second term represents the distribution matching method, with second term are based on aggregate statistics for the clone assets to ensure (a) the approximate scale of the mean and variance components are equivalent and (b) the second term has a maximum value of approximately one. Thus, mean return and volatility matching have approximately equal weight to each other.\$ Furthermore, these integers are calibrated such that one can define weights, $\omega_{i}$, in desired proportions quickly and easily.

The factor-based replication method used in this paper

$$
\text { Factor Fitness }=1\left(1-R^{2}\right)+0\left(75 *\left|\mu_{\mathrm{HF}}-\mu_{\text {clone }}\right|+25 *\left|\sigma_{\mathrm{HF}}-\sigma_{\text {clone }}\right|\right)
$$

$\mu_{i}\left(\sigma_{i}\right)$ representing the mean (standard deviation of) monthly returns, with $i$ representing either the target hedge fund (HF) or clone (clone). Thus, the ideal outcome in the second term is to find a clone portfolio that matches the target

†Note the function is signed such that minimization is the objective and that all fitness function values will be non-negative. One is not constrained to use a minimization function. sets $\omega_{\text {factor }}$ equal to 1 and $\omega_{\text {distribution }}$ equal to 0 .

The matching moments replication method used in this paper sets $\omega_{\text {factor }}$ equal to 0 and $\omega_{\text {distribution }}$ equal to 1 .

Note these pre-multipliers are based on the data used in this study for the reasons described. That is, they are based on a preassessment of all available data, not the in-sample data from each rolling period. They could (and likely will) change for alternate, customized GA implementations. 


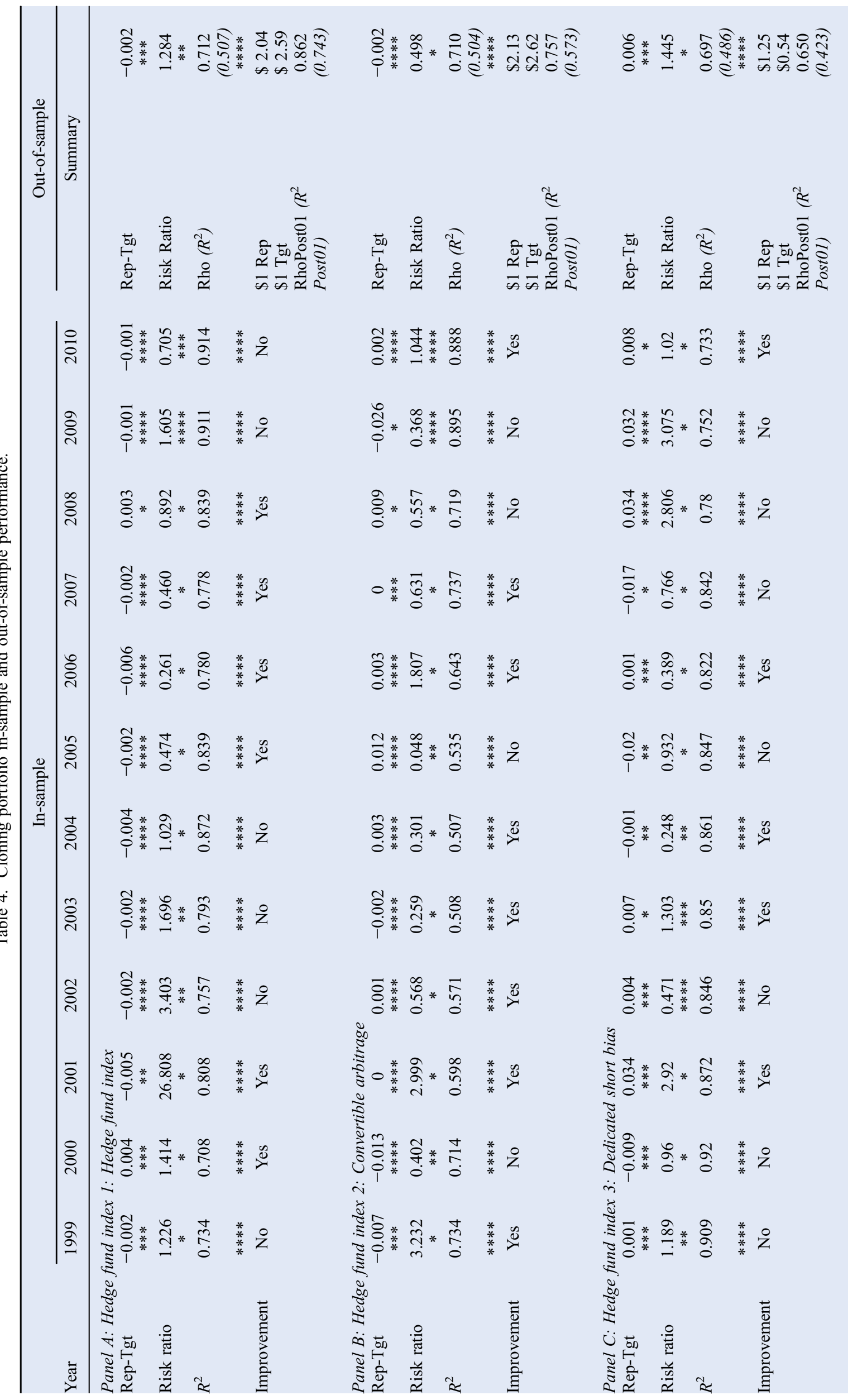




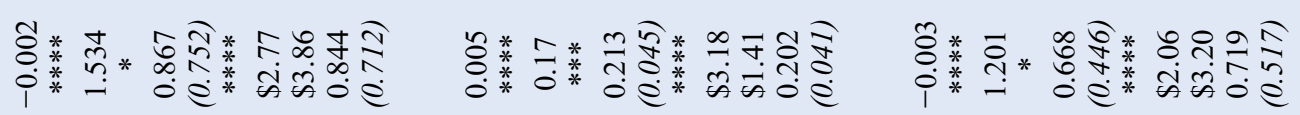

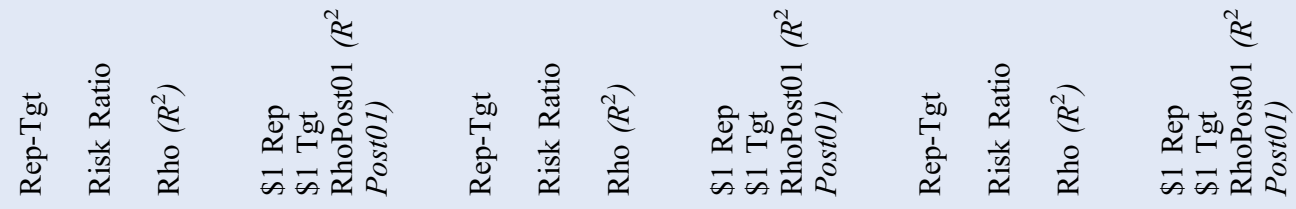

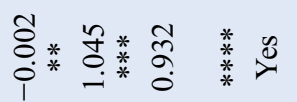

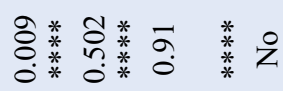

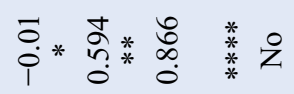

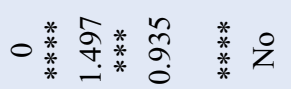

光* 菅*

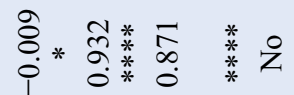

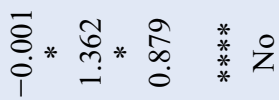

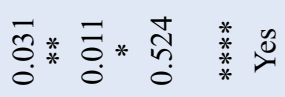

\&े*ڤ

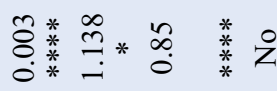

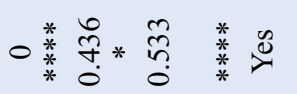

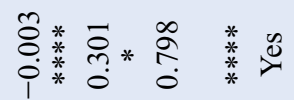

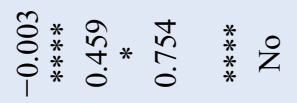

Бे*

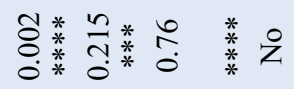

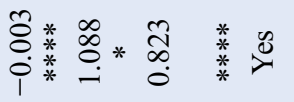

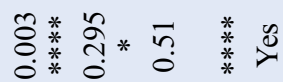

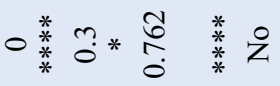

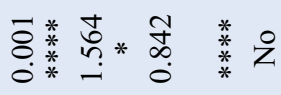

○

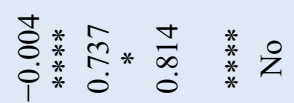

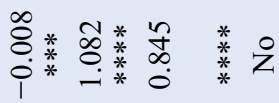

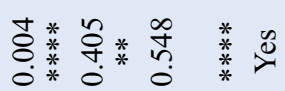

○蕃苔*

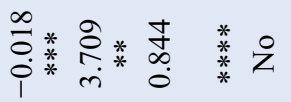

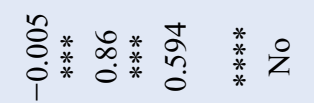

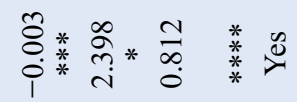

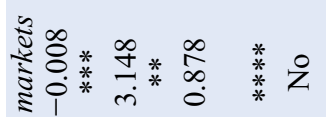

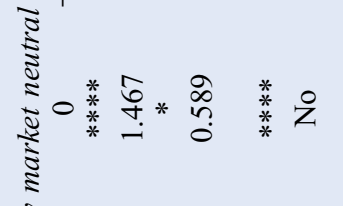

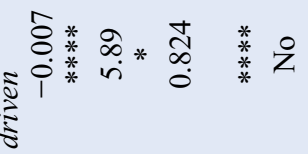

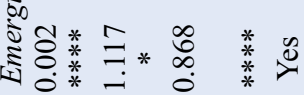

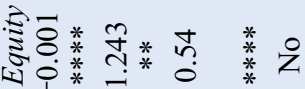

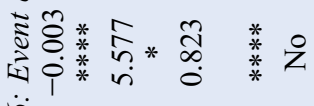

幽

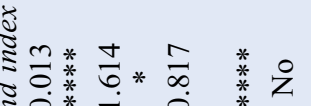

n

ฐँ๊

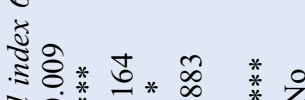

$\frac{\pi}{8}$

ह

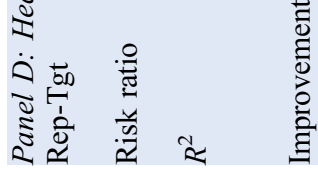

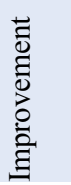

这

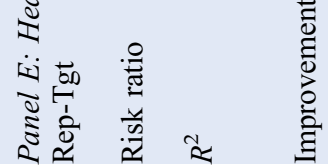

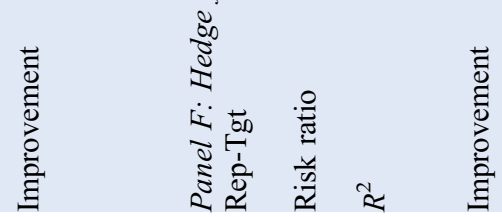

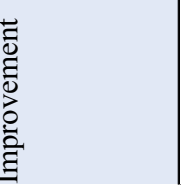




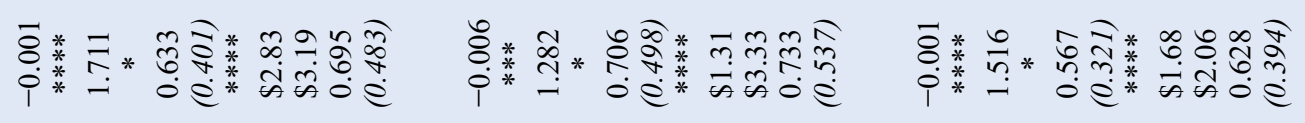

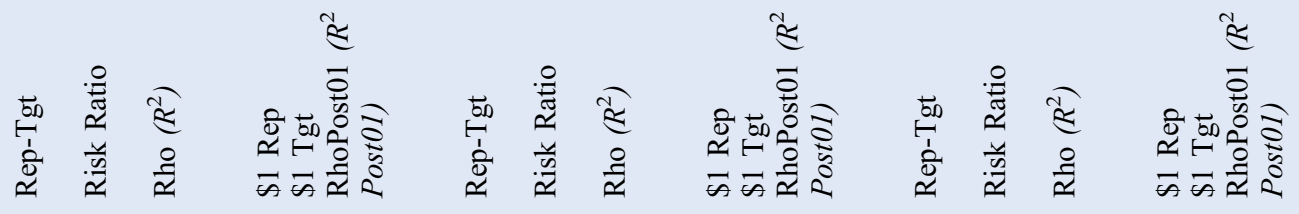

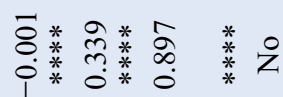

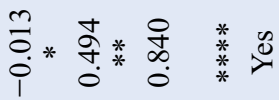

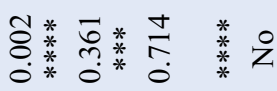

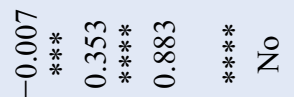

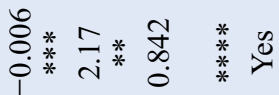

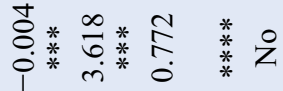

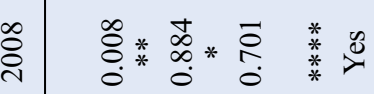

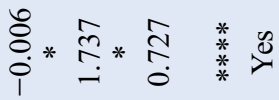

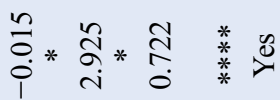

ڤิ)

官*

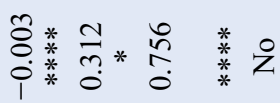

宅 章

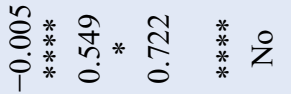

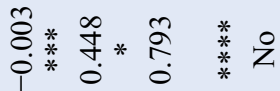

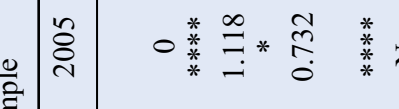

$\underset{\delta}{*} * \frac{\infty}{*} * \frac{+}{0} * \frac{*}{0}$ 菅

ఠ̊*

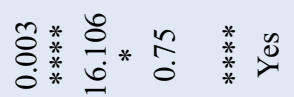

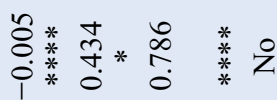

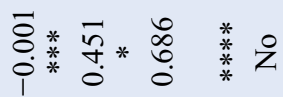

§ิ

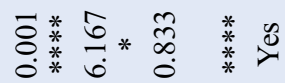

ఫ̊*

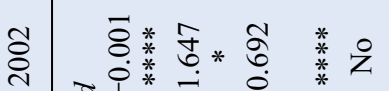

छे

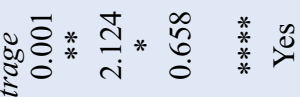

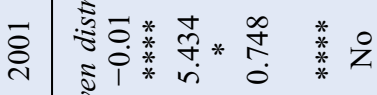

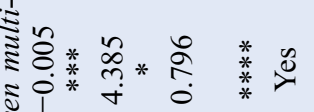

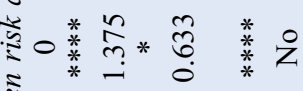

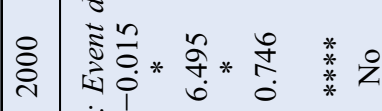

式告 है

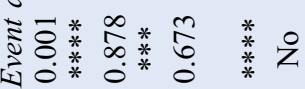

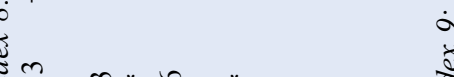

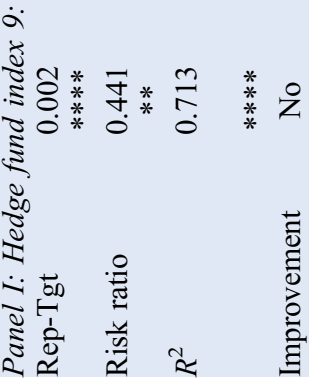




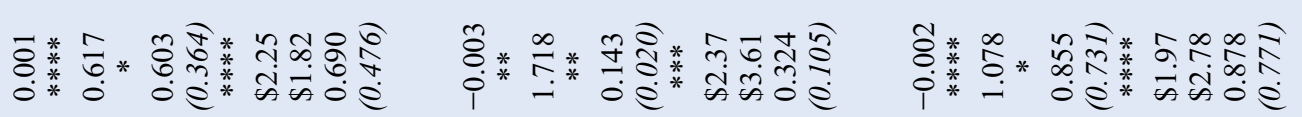

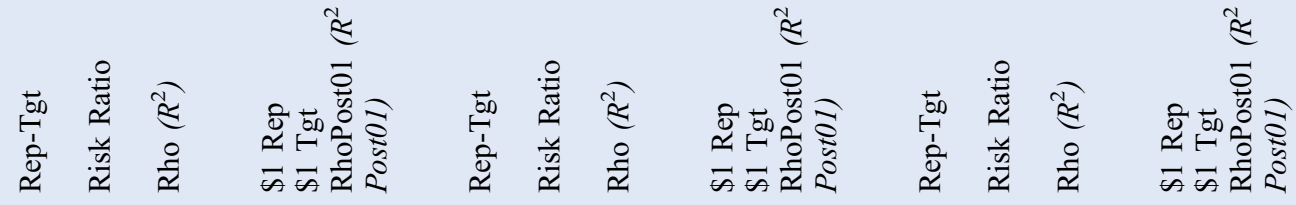

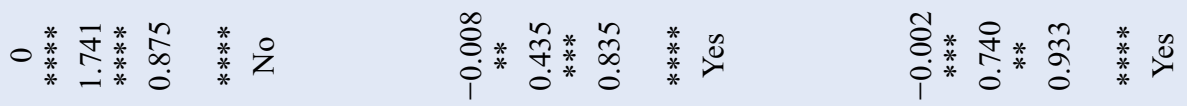

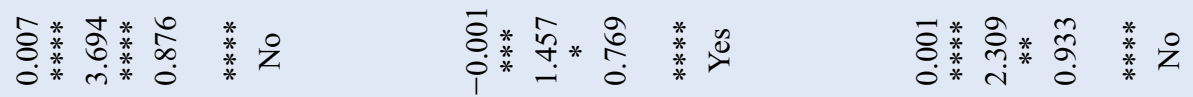

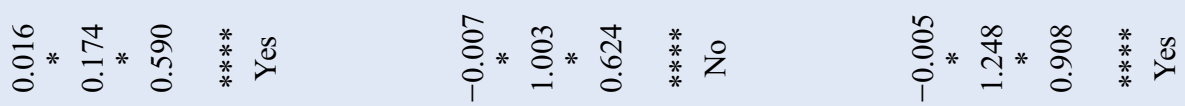

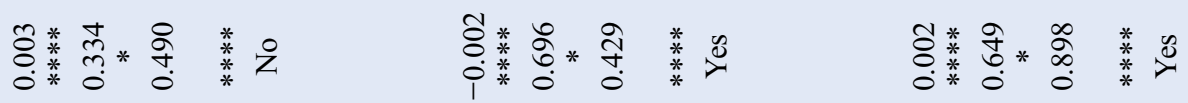

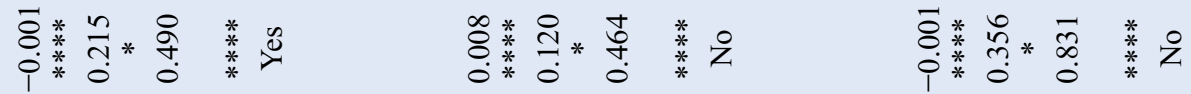

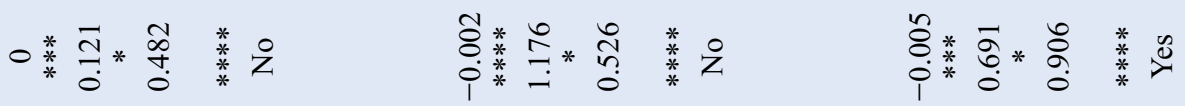

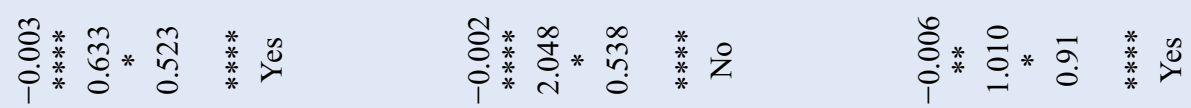

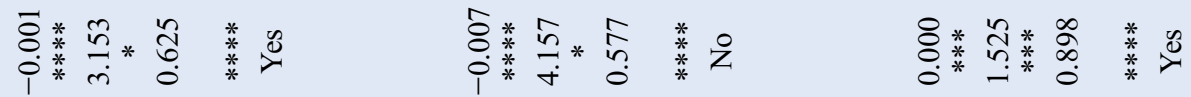

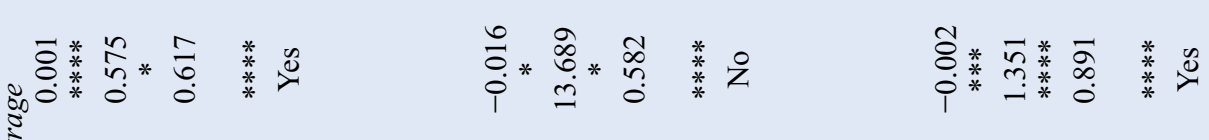

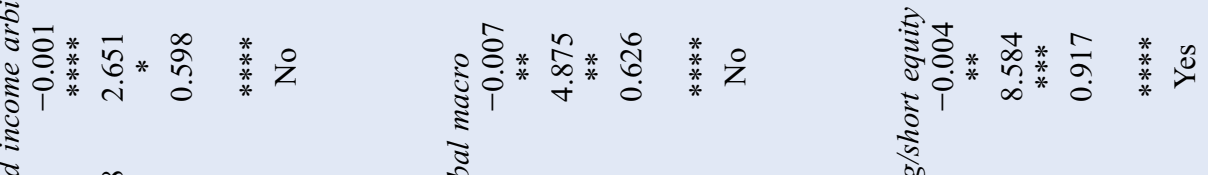

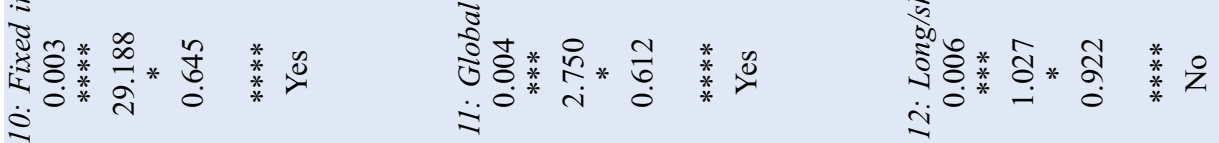

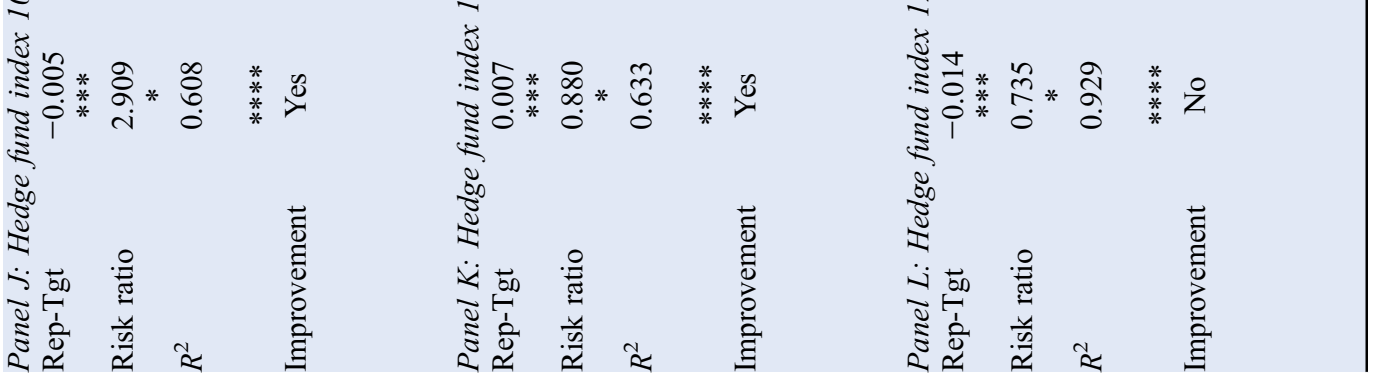




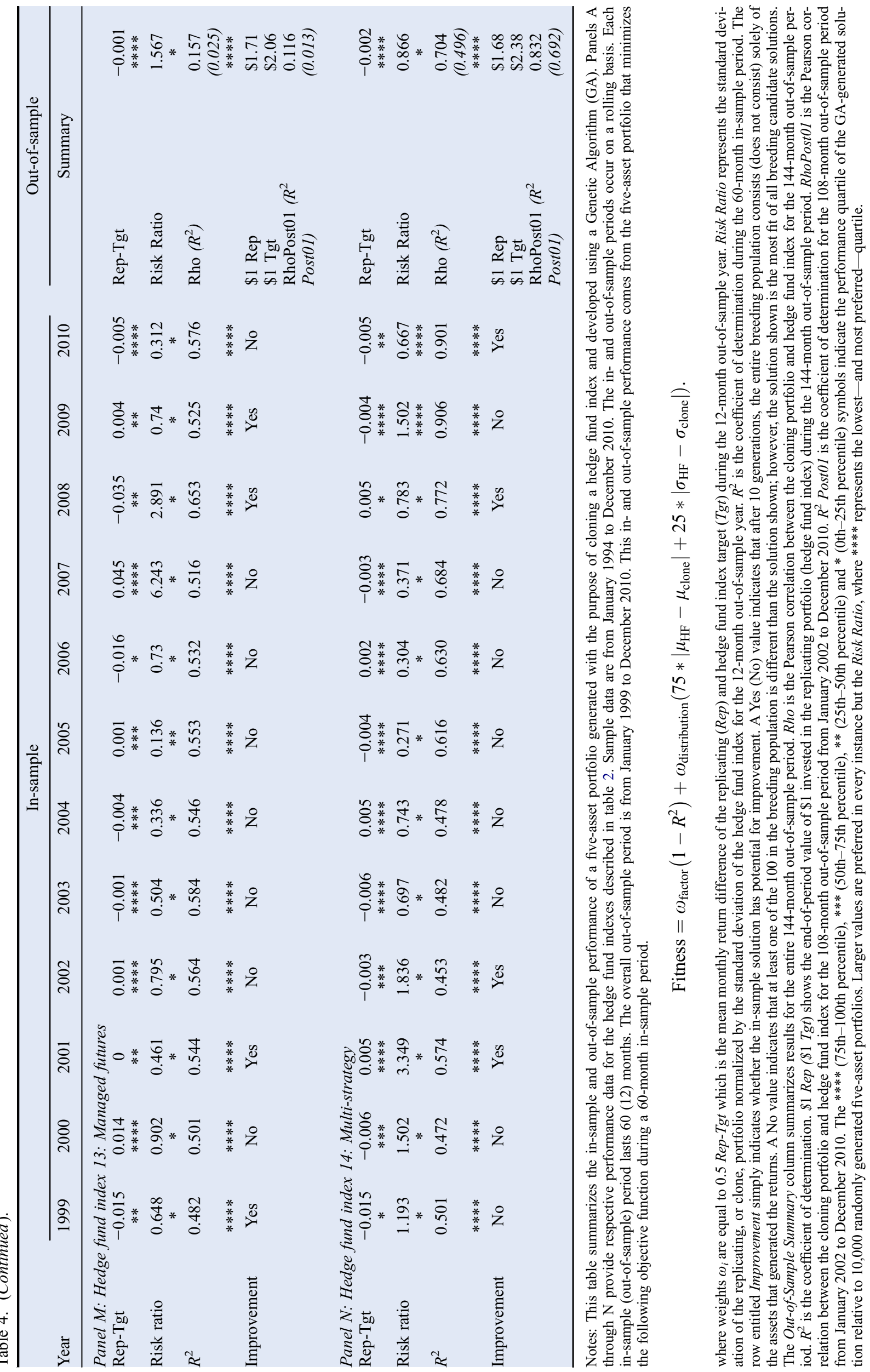


Matching Moments Fitness $=0\left(1-R^{2}\right)+1\left(75 *\left|\mu_{\mathrm{HF}}-\mu_{\text {clone }}\right|+25 *\left|\sigma_{\mathrm{HF}}-\sigma_{\text {clone }}\right|\right)$

Finally, the hybrid method subsequently shown in this paper sets both $\omega_{\text {factor }}$ and $\omega_{\text {distribution }}$ equal to 0.5 , lending equal weight to both the factor and distribution methods relative to each other. in-sample return series. Unlike Hasanhodzic and Lo (2007), we do not permit leverage given the focus on retail investors. And unlike Sharpe (1992), we do permit short positions in the assets. Relaxing this constraint relies on the

$$
\text { Hybrid Fitness }=0.5\left(1-R^{2}\right)+0.5\left(75 *\left|\mu_{\mathrm{HF}}-\mu_{\mathrm{clone}}\right|+25 *\left|\sigma_{\mathrm{HF}}-\sigma_{\mathrm{clone}}\right|\right)
$$

Obviously, limitless fitness function possibilities exist, which further the argument for the genetic algorithm method's flexibility and adaptability.

The goal of this study is not to claim that the Hybrid objective function is the best, but to show the power and versatility of the genetic algorithm to implement the desired cloning strategy.

Having defined the fitness (objective) function, the next step is to identify the potential solution set and a mechanism for deriving it. In the spirit of parsimony, we use a five-asset portfolio composed of combinations of the 4509 assets, which includes stocks (1689), bonds (9), mutual funds (2804) and factors (7) detailed in the Data section above. Since there exist over 15 quadrillion, or $\left(\begin{array}{c}4509 \\ 5\end{array}\right)=1.5497 \times 10^{16}$, possible combinations of these assets, evaluating each combination is not feasible at this time with our computing power. Respecting the Grummitt and Satchell (2011) conclusions that the Hasanhodzic and Lo (2007) factor-based model's effectiveness has extended to July 2010, we use a similar regression-based model to generate potential solutions. However, instead of limiting ourselves to 5,8 or 100 'factors', we include a very large set of over 4500 investable products.

To begin the iterative GA process, which Appendix A summarizes, we create an initial solution set population of 1000 randomly selected five-asset 'parent' portfolios, or candidate solutions. This set is defined as the initial population. For the 60-month in-sample period, we calculate each parent's fitness function value. To be clear, we use equation (5) to estimate the in-sample weights, $\alpha_{i}$, for each asset in the portfolio. Ret ${ }_{j, t}$ represents the return in month $t$ for asset $j$, where $j$ is either the hedge fund index $(H F)$ or one of the 4509 investable securities that form the clone portfolio. The $R^{2}$ value (i.e. between zero and one) from equation (5) is the first numerical component of the fitness function. Using the estimated weights, $\widehat{\alpha}_{i}$, from this regression multiplied by the actual asset return series allows us to generate an in-sample clone portfolio. The moments (i.e. mean and variance numerical values) in the second component of the fitness function come from this cloned portfolio's monthly
Payne (2010) finding that using this same GA process can lead to effective mutual fund replication using five stocks. We presume that one can take a short position in either these stocks, or perhaps a near-competitor. Incidentally, the results show that many of the short positions in the portfolios are offset with a long position in another asset in the same portfolio.

$$
\operatorname{Ret}_{\mathrm{HF}, t}=\alpha_{0}+\sum_{i=1}^{5} \alpha_{i}, \operatorname{Ret}_{i, t}, t=1,60 \text { months }
$$

Appendix A, Panel A shows a hypothetical example of the Initial Population, which consists of candidate solutions-or parents-indexed 1 to 1000 . The next five columns depict the index numbers for the randomly generated candidate solutions. The final column shows an associated Fitness Score for each candidate solution, which comes from the fitness function in (1).

Panel B shows hypothetical candidate solutions reordered according to fitness levels; again, the objective function in this case seeks to minimize the objective function, so the most fit candidate solutions have the smallest fitness function values. The population is then divided into two groups, called the 'breeding' population and 'nonbreeding' population. In this effort, we keep the 'best fit' $10 \%$ of all members (i.e. 100 portfolios) as the breeding population and consider the remaining $90 \%$ non-breeding. The generation of new candidate solutions is known in the GA literature as 'breeding'. New candidate solutions come only from the breeding population, and they replace the non-breeding $90 \%$ in one of two ways. Replacements for the non-breeding members are either better fit 'children' of the breeding members or randomly generated 'mutations'.

Panel $\mathrm{C}$ shows how the GA improves this population of initial candidate solutions by creating new candidates, or 'children', as partial combinations of existing population members. To create children, two randomly selected parents from the breeding population exchange up to three assets in their five-asset portfolios in a process called gene 'crossover'. This crossover creates two new and possibly unique children. If either or both of the children are more fit than 
their parents (i.e. more optimized fitness function value), then they replace a member of the non-breeding population. However, if either or both of the children are less fit than their parents, then a mutation is inserted into the non-breeding population. This mutation is a new randomly generated five-asset portfolio. Once either a child or mutation has replaced all of the of the non-breeding population members, the system has created a new generation. This new generation appears just like the initial population in Panel A, except it has replaced $90 \%$ of the total population with either children or mutations.

The best fit members of the overall population should improve through time as measured by the fitness function, which in turn improves the average fitness level of the breeding population. In this algorithm, we artificially constrain the process to end after 10 generations, but even with doing so, it turns out that the breeding sample converges to an immutable solution (i.e. every member of the breeding population consists of the same five assets or genes) approximately one-half the time. While we do not run a proof of concept demonstration in this paper, Payne (2010) describes the process in further detail and demonstrates the GA efficacy for an analogous problem using a different fitness function tailored to its purpose.

To address concerns about the potential time-varying nature of the relationships between the investable securities and the hedge fund indexes as well as any look-ahead bias, this GA implements a rolling approach to generate the outof-sample results. More specifically, to allow for longerterm stability between the cloning portfolio and hedge fund, it uses a 60 -month in-sample or evaluation period followed by a 12-month out-of-sample period. It continues rolling both periods forward by 12 months at a time, implying annual changes in portfolio holdings. Since our data span January 1994-December 2010, the first in-sample (out-ofsample) period spans January 1994-December 1998 (January-December 1999); the second in-sample (out-ofsample) period spans January 1995-December 1999 (January-December 2000). Continuing in this fashion leads to 144 out-of-sample months of a clone portfolio. This outof-sample period exhibits a time of what Kat and Palaro (2006a) call 'bizarre behavior' in the market and world. It saw the boom in the late-1990s, followed by the bust in the early 2000s, a recovery until the 2007 fall and most recently another (hopeful) recovery. Relevant crises have included Thailand, Russia, LTCM, 9/11, Iraq and Afghanistan wars, US recession and European debt, to highlight a few. Recognizing that transactions costs affect retail investors, we are implementing a system that accords with a retail investing rule of thumb to rebalance annually, thereby controlling tax and transaction cost impacts. Thus, our outof-sample portfolio is rebalanced in January of every outof-sample year for a total of 12 times over the entire period. This aspect of our solution has considerable appeal given the Kat and Palaro (2006a) portfolios involve trading an average of over 200 futures contracts across seven asset categories every day.

As Bauer (1994) highlights, there certainly exists a major caveat to GAs. Because of their iterative nature and the sensitivity to the user-defined inputs (e.g. initial population, breeding population, amount of gene crossover, mutation frequency and method, etc.), there is a chance that a GA will not find the single optimal solution. However, as he demonstrates, it will generally find near-optimal solutions, and in some cases, the optimal solution. It is possible the GA will converge too quickly on a sub-optimal solution. As he further articulates, however, in a practical sense achieving the time-consuming optimal solution can become lesspreferred than the quickly developed acceptable one. Thankfully researchers such as De Jong (1975) have quite effectively established appropriate input values and quantified the sensitivity to changes in them. Given the unique problem in this paper, the GA methodology generally adheres to convention and uses these recommended input values. $\dagger$

\section{Results}

In general, the results vary among the different hedge fund indexes, but they are encouraging relative to prior-published efforts. First, we discuss the Kolmogorov-Smirnov (K-S) test results. Then, we focus on a fund-by-fund analysis using the three replication methods; Factors, Hybrid and Moments.

\subsection{Kolmogorov-Smirnov $(K-S)$ test}

If matching return distributions versus month-to-month performance is the replication objective, then table 3 shows the results for Kolmogorov-Smirnov $(\mathrm{K}-\mathrm{S})$ tests of whether the out-of-sample returns of the replicating portfolio and respective hedge fund index come from the same distribution. This table shows K-S results for all three aforementioned methods: Factors, Hybrid and Moments. Using only the Factors method fitness function [i.e. equation (2)] in the genetic algorithm enables one to replicate five out of the 14 hedge fund indexes. As expected, this number grows- to nine-using the Moments fitness function. Using a Hybrid of both methods (i.e. equations (4)) also leads to nine effective out-of-sample replication portfolios in terms of distributions. Interestingly, there are situations (Equity Neutral, Event-Driven Multi-Strategy and Global Macro) where the moments-only method provided statistically similar replicating portfolios, while the hybrid and factors methods generated statistically different portfolios. We posit this result occurs due to the equal weighting of the two terms in the objective function and is, therefore, an adjustment one could make going forward. In addition, using a hybrid approach allows one to clone the Event Driven, Managed Futures and Multi-Strategy hedge fund indexes, none of which the Factors or Moments methods could achieve when used by themselves.

$\dagger$ Specifically, as described above, this implementation allows for a $10 \%$ breeding population within its 1000 member overall population. Additionally, it allows for up to $60 \%$ (randomized) genetic crossover (i.e. each five-gene 'child' pair can result from swapping one, two or three of the genes it inherits from its two parents). 
The genetic algorithm did not effectively replicate the Convertible Arbitrage or Fixed Income Arbitrage strategies according to these $\mathrm{K}-\mathrm{S}$ tests. While their cloning portfolio outperformed the target hedge fund index during the 17-month out-of-sample period between July 2000 and December 2001, Agarwal and Naik (2004) also indicate the biggest difference between their clones and the hedge fund index occurred with the Convertible Arbitrage index. Similar to their results, $t$-tests for differences in mean monthly out-of-sample returns using this genetic algorithm methods show no differences in 13 of 14 hedge fund indexes; only the Event Driven Multi-Strategy shows a significant difference in mean monthly returns relative to the cloning portfolio.

In figure 1, Panel A shows some selected previous studies that have replicated hedge fund returns. We divide these studies by the method and out-of-sample $R^{2}$, which unfortunately most of these studies do not report for comparison purposes. Panel B shows an overview of the in-sample and out-of-sample results generated by the hybrid replication method detailed in this study. The hybrid method performs favourably compared with the documented out-of-sample $R^{2}$.

\subsection{Fund-by-fund analysis}

5.2.1. Overview of replication statistics. This section discusses the funds replication. Table 4, Panels A-L provide the results for the genetic algorithm effort to clone the overall Hedge Fund Index and the Hedge Fund Index Strategies for the 144 months spanning January 1999-December 2010 using the fitness function in equation (4), where the factors are $\omega_{\text {factor }}=\omega_{\text {distribution }}=0.5 . \dagger$ Again, we call this the hybrid fitness function, because it synthesizes both commonly used replication methods, the factor and moments methods. The column labelled 1999 shows the genetic algorithm-generated replicating portfolio mean monthly out-ofsample return during this 12-month period. For robustness purposes, we randomly generated 10,000 five-asset portfolios to compete with the genetic algorithm-generated fiveasset solution. The one-to-four asterisks shown underneath portfolio metrics in the tables indicate which quartile of random portfolios contains the genetic algorithm-generated out-of-sample solution. Four asterisks is always preferred, in the sense it is the quartile with the highest returns, lowest standard deviation and highest correlation or $R^{2}$ values. For instance, table 4 Panel A which is the replication of the overall Hedge Fund Index shows the Rep-Tgt value of -0.002 for 1999 is in the third quartile, or between the 50th and 75th percentiles, of all 10,000 random portfolios. The Risk Ratio shows the annual out-of-sample standard deviation ratio of the cloning portfolio to the target hedge fund index. The next metric is the coefficient of variation, $R^{2}$, for the in-sample period. This value helps compare these results with other published efforts that often evaluate

$\dagger$ Results for the factor method (i.e. $\omega_{\text {factor }}=1 ; \omega_{\text {distribution }}=0$ ) and moments method (i.e. $\omega_{\text {factor }}=0 ; \omega_{\text {distribution }}=1$ ) are available upon request. their tracking performance using this metric. As with the others, the asterisks show the performance relative to the 10,000 randomly generated portfolios. The row entitled Improvement simply indicates whether the in-sample solution has potential for improvement. A Yes (No) value indicates that after 10 generations, the entire breeding population consists (does not consist) solely of the assets that generated the returns. A No value indicates that at least one of the 100 in the breeding population is different than the solution shown; however, the solution shown is the most fit of all breeding candidate solutions. The Out-ofSample Summary section provides the entire 144-month out-of-sample values for Rep-Tgt, Risk Ratio and Rho, which is the correlation between hedge fund index target and the cloning portfolio, along with their quartile measures against the random portfolios. It also provides the December 2010 end-of-period value for one dollar invested in January 1999 in the cloning, or representative portfolio (\$1 Rep), and the target hedge fund index $(\$ 1 T g t)$. Due to the apparently anomalous hedge fund index behaviour in the 2000-2001 timeframe, we also provide the correlation between January 2002 and December 2010 for reference (RhoPost01).

5.2.2. Funds replicated with three methods. Either replication tool is effective for the Hedge Fund Index, Dedicated Short Bias, Emerging Markets, Event Driven Risk Arbitrage and the Long/Short Equity indexes from a return distribution standpoint as seen in the $\mathrm{K}-\mathrm{S}$ test, table 3 . The hybrid replication statistics shed further light on the replication relationship.

Visually, the cloning portfolio for the Hedge Fund Index matches quite well after the early 2001 divergence (see figure 2, Panel A). The results in table 4, Panel A support this conclusion given the relatively similar returns (statistically insignificant difference of -20 basis points per month), the Risk Ratio that is fairly close to 1 at 1.284 , a correlation of 0.712 that goes to 0.862 post-2001 and the end-of-period proximity of $\$ 1$ invested in the clone $(\$ 2.04)$ to $\$ 1$ invested in the hedge fund index $(\$ 2.59)$. Thus, the genetic algorithm technique makes it possible for a retail investor to create a portfolio that tracks the Hedge Fund Index out-of-sample.

As for the Dedicated Short Bias index, the visual match between the clone and target hedge fund returns is not as striking as for the Hedge Fund Index (figure 2, Panel C). Nevertheless, this table also shows the clone outperforms the target -60 basis points per month and $\$ 1.25$ end-ofperiod vs. $\$ 0.54$ in the target index-and maintains a correlation of 0.697 across the out-of-sample period.

The Emerging Markets Index represents another closely replicable series. The monthly match in figure 2, Panel D shows monthly deviations occur primarily early and late in the out-of-sample period, but the deviations are mainly more extreme movements in the same direction as the target (i.e. higher highs and lower lows). The differences net out to make the mean monthly return of -20 basis points insignificantly different than the target across the 144-month out-of-sample period. And, while the risk level for the clone 
is higher than for the target, the correlation value is also high at 0.867 (0.844 post-2001).

The Event Driven Risk Arbitrage index tends to underperform the clone early, but outperforms it late, epitomized by the extreme downturn in September 2008, leading to an insignificant mean difference in monthly returns of -10 basis points. The out-of-sample correlation measures 0.567 , and the clone's risk is higher than the index.

Finally, the Long/Short equity index cloning portfolio has a statistically indifferent mean monthly return compared with the index itself, and approximately the same amount of risk with a Risk Ratio of 1.078 . They move together closely with an out-of-sample correlation of 0.855 ( 0.878 post-2001).

5.2.3. Funds replicated with two methods. The remaining funds represent the sub-sample where the cloning method matters when looking at the $\mathrm{K}-\mathrm{S}$ results, table 3 . In none of these cases does the factors-only method form a cloning portfolio with statistically equivalent returns as the index target. These results indicate a moments-only fitness function is most appropriate for the Equity Market Neutral Index, Event Driven Multi-Strategy Index and Global Macro Index.

The tremendous October 2008 drop in the Equity Market Neutral Index makes visual assessment difficult (figure 2, Panel E). It also explains the cloning portfolio's substantial outperformance in terms of mean monthly return (50 basis points), the end-of-period dollar value ( $\$ 3.18$ for the clone vs. $\$ 1.41$ for the index) and risk (Risk Ratio of 0.170) shown in table 4, Panel E.

Next, the Event Driven Multi-Strategy Index clone tracks its target much better in-sample that out-of-sample in terms of $R^{2}$ values, possibly due to the flexibility imbedded in this hedge fund strategy. The cloning portfolio's early underperformance (see figure 2, Panel $\mathrm{H}$ ) improves slightly for a few years before underperforming again at the end of the out-of-sample period. This performance ultimately leads to a large mean difference in monthly returns $(-60$ basis points) despite the relatively matched risk level (Risk Ratio $=1.282)$ in table 4, Panel $\mathrm{H}$. The correlations are 0.706 (0.733 post-2001).

The final index where a moments-only approach is appropriate is the Global Macro Index. It is clear from figure 2, Panel $\mathrm{K}$ that matching returns by month does not occur nearly as well as for other indexes, and the low correlations in table 4, Panel $\mathrm{K}$ re-affirm this idea. The mean monthly return difference of -30 basis points is statistically insignificant, even though the Risk Ratio is 1.718 and one dollar invested in the clone leads to an end-of-period wealth (\$2.37) that is lower than the hedge fund index (\$3.61).

The lone index in which either a hybrid or moments-only method appears to work well out-of-sample is the Event Driven Distressed Index. Figure 2, Panel G shows the outof-sample monthly behaviour is quite similar between the clone and the index post-2004, despite some noticeable divergence in certain months early in the out-of-sample period (e.g. December 1999, November 2000 and January 2004). These early divergent results also come through in table 4, Panel G, where the early out-of-sample years show notable clone underperformance. Nevertheless, across the whole out-of-sample period there remains an insignificant -10 basis point difference between the clone and target index, and the end-of-period dollar value is relatively close at $\$ 2.83(\$ 3.19)$ for the clone index.

5.2.4. Funds replicated only with hybrid method. A hybrid method that considers both the month-by-month matching ability and the return distribution uniquely creates effective cloning portfolios for the Event Driven Index, Managed Futures Index and Multi-Strategy Index. Note that this genetic algorithm implementation is the only explicit method we are aware of that simultaneously and quantitatively considers both the factor-based and moments-based approaches.

The clone portfolio for the Event Driven Index generally follows the index itself month-to-month in figure 2, Panel $\mathrm{F}$; however, the notable underperformance late in the outof-sample period is evident and induces the insignificant -30 basis point mean monthly difference in the clone and index return series. The two series have similar risk with a 1.201 Risk Factor value.

Interestingly, the genetic algorithm is able to clone the returns for the Managed Futures Index on a return distribution basis. Figure 2, Panel M shows weak month-to-month tracking, a result confirmed by the very low out-of-sample correlation of 0.157 in table 4, Panel M. Although the genetic algorithm also had a relatively difficult time tracking this fund in-sample (i.e. low $R^{2}$ values), overall the difference in mean monthly return $(-10$ basis points $)$ is insignificant, the Risk Ratio is 1.567 and the end-of-period portfolio value of $\$ 1$ is reasonably close at $\$ 1.71$ for the clone and $\$ 2.06$ for the index.

Finally, the results in figure 2, Panel $\mathrm{N}$ show the clone's tracking of the Multi-Strategy Index improves over the outof-sample period, including during the extreme downturn in late 2008 and the substantial recovery during the first half of 2009. The clone for this index represents an instance where it has less risk than the index (Risk Ratio of 0.866). The out-of-sample difference of -20 basis points in mean monthly return is insignificant, and the correlation between the clone and index is 0.704 (0.832 post-2001).

5.2.5. Struggling replications. The genetic algorithm replication method struggles the most with the Convertible Arbitrage and Fixed Income Arbitrage strategies. The cloning portfolios' returns do not match those of the respective hedge fund index. The Convertible Arbitrage clone performance clearly lags during the difficult 2000 and 2009 markets (figure 2, Panel B) to the tune of 1.3 and $2.6 \%$ per month, on average. The significant divergence in these two years notwithstanding, the out-of-sample mean return difference (negative 20 basis points per month) is statistically zero, and the correlation (0.710) is quite high. Both measures rate very well relative to random portfolio selection, as expected. The Fixed Income replicating portfolio differs in the other direction-it significantly outperforms the 
hedge fund index across the out-of-sample period in mean monthly return at positive 10 basis points (table 4, Panel J). Due to its tremendous volatility in both 2000 and 2009, overall it is riskier than both the target hedge fund and the majority of the 10,000 random portfolios. Despite these differences, the out-of-sample correlation between the index and cloning portfolio remains respectable at 0.603 .

\section{Conclusion}

This paper uses a genetic algorithm that sorts through 4509 investable stocks, bonds and mutual funds to replicate hedge fund returns. The genetic algorithm in this paper permits a hybrid approach that values performance replication on a month-to-month basis as well in terms of matching the return distribution, synthesizing and combining two methods that prior research has implemented independently. We find that implementing such a hybrid approach leads to effective out-of-sample cloning, which neither the factor nor moments methods in isolation could replicate from a statistical standpoint. While its solutions are not perfect, they match up quite well, providing a novel starting point for practitioners and academics alike.

Clearly, the application of the genetic algorithm in this paper is but one drop in an ocean of possibilities. We recognize this paper demonstrates just one application of a very flexible genetic algorithm technique. We leave the sensitivity analysis and methodological modifications to future efforts. Suffice it to say these possibilities include but are not limited to: changing the in-sample period, altering the fitness function, enlarging the portfolio, growing the candidate solution population, enlarging the breeding population, changing the mutation process, adding additional constraints (e.g. no short-selling) or changing the assets under consideration. Further, this method can also be used to identify managers whose returns cannot be replicated.

\section{Acknowledgement}

We would like to thank Keith Black, George McCabe, Alex Gurvich, John Geppert, Geoffrey Friesen, Richard DeFusco, participants at the 2013 Midwest Finance Association Conference, participants at the 2013 Applied FMA conference. All mistakes are ours. This work was supported in part by Grant Agency of the Czech Republic [14-31783S]. The views expressed in this paper are those of the authors and do not necessarily reflect the official policy or position of the Air Force, the Department of Defense or the US Government. Support from GACR grant number 14-31783S is gratefully acknowledged.

\section{References}

Agarwal, V., Boyson, N.M. and Naik, N.Y., Hedge funds for retail investors? An examination of hedged mutual funds. J. Financ. Quant. Anal., 2009, 44, 273-305.
Agarwal, V. and Naik, N.Y., Risk and portfolio decisions involving hedge funds. Rev. Financ. Stud, 2004, 17, 63-98.

Aggarwal, R.K. and Jorion, P., Is there a cost to transparency? Financ. Anal. J., 2012, 68, 108-123.

Amenc, N., El Bied, S. and Martellini, L., Predictability in hedge fund returns. Financ. Anal. J., 2003, 59, 32-46.

Amenc, N., Gehin, W., Martellini, L. and Meyfredi, J.-C., Passive hedge fund replication: A critical assessment of existing techniques. J. Altern. Invest., 2008, 11, 69-83.

Amin, G.S. and Kat, H.M., Hedge fund performance 1990-2000: Do the "money machines" really add value? J. Financ. Quant. Anal., 2003, 38, 251-274.

Bauer, R.J., Genetic Algorithms and Investment Strategies, 1994 (John Wiley \& Sons: New York).

Carhart, M.M., On persistence in mutual fund performance. $J$. Financ., 1997, 52, 57-82.

Chong, J. and Phillips, G.M., Can typical households earn hedge fund returns? An analysis of the Eta ${ }^{\circledR}$ replication approach. $J$. Derivatives Hedge Funds, 2012, 18, 53-72.

De Jong, K.A., An analysis of the behavior of a class of genetic adaptive systems. PhD Thesis, University of Michigan, 1975.

Duarte, J., Longstaff, F.A. and Fan, Y., Risk and return in fixedincome arbitrage: Nickels in front of a steam roller. Rev. Financ. Stud., 2007, 20, 769-811.

Dybvig, P.H., Inefficient dynamic portfolio strategies or how to throw away a million dollars in the stock market. Rev. Financ. Stud., 1988, 1, 67-88.

Fama, E.F. and French, K.R., Common risk factors in the returns on stocks and bonds. J. Financ. Econ., 1993, 33, 3-56.

Fung, W. and Hsieh, D.A., Asset-based style factors for hedge funds. Financ. Anal. J., 2002, 58, 16-27.

Gibson Brandon, R. and Gyger, S., Optimal hedge fund portfolios under liquidation risk. Quant. Finance, 2011, 11, 53-67.

Goodworth, T.R.J. and Jones, C.M., Factor-based, non-parametric risk measurement framework for hedge funds and fund-of-funds. Eur. J. Financ., 2007, 13, 645-655.

Grummitt, J. and Satchell, S., Hedge fund replication. J. Derivatives Hedge Funds, 2011, 17, 219-236.

Hasanhodzic, J. and Lo, A.W., Can hedge fund returns be replicated? The linear case. Journal of Investment Management, $2007,5,5-45$.

Holland, J.H., Adaptation in Natural and Artificial Systems, 1975 (University of Michigan: Ann Arbor, MI).

Kat, H.M. and Palaro, H.P., Who needs hedge funds? A copulabased approach to hedge fund return replication. Alternative Investment Research Centre Working paper No. 27, Cass Business School, City University, London, 2005.

Kat, H.M. and Palaro, H.P., Replication and evaluation of fund of hedge funds returns. Alternative Investment Research Centre Working paper No. 28, Cass Business School, City University, London, 2006a.

Kat, H.M. and Palaro, H.P., Superstars or average Joes?: A replication-based performance evaluation of 1917 individual hedge funds. Alternative Investment Research Centre Working paper No. 30, Cass Business School, City University, London, 2006b.

Mitchell, M.L. and Pulvino, T.C., Characteristics of risk and return in risk arbitrage. J. Financ., 2001, 56, 2135-2175.

Payne, B.C., Two essays on health care costs and asset returns. $\mathrm{PhD}$ Dissertation, College of Business Administration, University of Nebraska-Lincoln, 2010.

Pontiff, J. and Shall, L.D., Book-to-market ratios as predictors of market returns. J. Financ. Econ., 1998, 49, 141-160.

Rafaely, B. and Bennell, J.A., Optimisation of FTSE 100 tracker funds: A comparison of genetic algorithms and quadratic programming. Managerial Financ., 2006, 32(6), 477-492.

Sharpe, W.F., Asset allocation: Management style and performance measurement. J. Portfol. Manage., 1992, 18, 7-19.

Takahashi, A. and Yamamoto, K., Hedge fund replication. In The Recent Trend of Hedge Fund Strategies, pp. 57-95, 2008 (Nova Science Publishers: New York). 


\section{Appendix A}

\section{Genetic Algorithm Process}

This figure summarizes the iterative Genetic Algorithm (GA) process to generate hedge fund index tracking portfolios. Panel A shows an example of the set-up of the initial candidate population. Panel B shows the initial candidate population ranked according to fitness. The top fit candidates are called the breeding population. Panel $\mathrm{C}$ shows an example of pairing using a gene crossover. Candidate 1000 and 2 constitute the first pairing based on their best fitness. They produce two offspring or alternative solutions by the process of crossover. With a crossover of 2, Ret(i) and Ret (j) from candidate 1000 and 2 are swapped while the remaining three assets remain the same.

Panel A: Initial population

\begin{tabular}{lcccccc}
\hline & \multicolumn{5}{c}{ Initial population } \\
\cline { 2 - 6 } Candidate solution $\#$ & \multicolumn{5}{c}{ Assets included in the candidate solution } \\
\cline { 2 - 6 } & Ret $(i)$ & Ret $(j)$ & Ret $(k)$ & Ret $(l)$ & Ret $(m)$ & Fitness score \\
\hline 1 & 1 & 7 & 25 & 36 & 41 & 1.02 \\
3 & 23 & 9 & 7 & 29 & 31 & 0.8 \\
$*$ & 7 & 3 & 2 & 19 & 15 & $*$ \\
$*$ & $*$ & $*$ & $*$ & $*$ & $*$ & $*$ \\
721 & $*$ & $*$ & $*$ & $*$ & 38 & $*$ \\
$*$ & $*$ & $*$ & $*$ & 9 & $*$ & $*$ \\
1000 & 22 & 15 & 14 & $*$ & & $*$ \\
\hline
\end{tabular}

Panel B: Initial population re-ordered by fitness level

\begin{tabular}{lcccccc}
\hline & \multicolumn{5}{c}{ Assets included in the candidate solution } \\
\cline { 2 - 5 } Candidate solution \# & Ret $(i)$ & Ret $(j)$ & Ret $(k)$ & Ret $(l)$ & Ret $(m)$ & Fitness score \\
\hline 1000 & 2 & 6 & 28 & 7 & 11 & 0.25 \\
2 & 23 & 9 & 7 & 29 & 31 & 0.8 \\
1 & 1 & 7 & 25 & 36 & 41 & 1.02 \\
721 & 22 & 15 & 14 & 9 & 38 & 1.05 \\
3 & 7 & 3 & 2 & 19 & 15 & 2 \\
$*$ & $*$ & $*$ & $*$ & $*$ & $*$ & $*$ \\
\hline
\end{tabular}

Panel C: Example of pairing using gene crossover

\begin{tabular}{lcccccc}
\hline & \multicolumn{5}{c}{ Assets included in the candidate solution } \\
\cline { 2 - 6 } Candidate solution \# & Ret $(i)$ & Ret $(j)$ & Ret $(k)$ & Ret $(l)$ & Ret $(m)$ & Fitness score \\
\hline 1000 & 2 & 6 & 28 & 7 & 11 & 0.25 \\
2 & 23 & 9 & 7 & 29 & 31 & 0.8 \\
Offspring 1 & 23 & 9 & 28 & 7 & 11 & 31 \\
Offspring 2 & 2 & 6 & 7 & 29 & \\
\hline
\end{tabular}

